\title{
EL GÉNERO FICUS (MORACEAE) EN EL ESTADO DE MORELOS, MÉXICO
}

\author{
Eva María Piedra-Malagón ${ }^{1}$, Rolando Ramírez Rodríguez ${ }^{2}$ Y \\ GUILlERmo IBARRA-MANRÍQUeZ ${ }^{3}$
}

${ }^{1}$ Instituto de Ecología A.C., Centro Regional del Bajío

Avenida Lázaro Cárdenas 235, 61600 Pátzcuaro, Michoacán

empm_educam@yahoo.com.mx

${ }^{2}$ Universidad Autónoma del Estado de Morelos

Centro de Educación Ambiental e Investigación Sierra de Huautla

Avenida Universidad 1001, Colonia Chamilpa, 62209 Cuernavaca, Morelos

rolando@buzon.uaem.mx

${ }^{3}$ Universidad Nacional Autónoma de México, Centro de Investigaciones en

Ecosistemas. Antigua carretera a Pátzcuaro 8701, Colonia San José de la Huerta, 58190 Morelia, Michoacán, gibarra@oikos.unam.mx

\section{RESUMEN}

El género Ficus (Moraceae) es un elemento característico de las zonas tropicales del mundo; en México se distribuye prácticamente en todo su territorio y en una amplia diversidad de hábitats. Con base en una revisión de bibliografía florístico-taxonómica y de los ejemplares de herbario provenientes del estado de Morelos, depositados en ENCB, HUMO, MEXU, MORE, UAMIZ y colectas botánicas adicionales, se reconocen ocho especies nativas de Ficus para esta entidad. Dos de ellas pertenecen al subgénero Pharmacosycea (Ficus insipida Willd. y F. maxima Mill.) y seis al subgénero Urostigma (F. cotinifolia Kunth, F. glycicarpa (Miq.) Miq., F. pertusa L.f., F. petiolaris Kunth, F. trigonata L. y Ficus sp.). Se incluye una clave de identificación para los subgéneros y especies, así como descripciones morfológicas detalladas y fotografías de cada una de estas últimas, con información sobre su distribución, hábitat, fenología y usos.

Palabras clave: Ficus, florística, México, Moraceae, Morelos.

\section{ABSTRACT}

The genus Ficus (Moraceae) is a typical component of tropical areas of our planet. The Mexican species of this taxon are found practically in all country, occurring in several 
of their habitats. Based on the revision of floristic and taxonomic literature, herbarium specimens deposited in ENCB, HUMO, MEXU, MORE, UAMIZ, and field explorations, a floristic study of the species of Ficus in Morelos state is presented. We recognize eight native species: two belong to subgenus Pharmacosycea (Ficus insipida Willd. and F. maxima Mill.) and six are included in subgenus Urostigma (F. cotinifolia Kunth, F. glycicarpa (Miq.) Miq., F. pertusa L.f., F. petiolaris Kunth, F. trigonata L., and Ficus sp.). The study contains an identification key to taxonomic levels of subgenus and species. We offer also for each species a description with detailed morphological information, photographs, and data over their distribution, habitat, phenology, and uses.

Key words: Ficus, floristics, Mexico, Moraceae, Morelos.

\section{INTRODUCCIÓN}

Dentro de la literatura ecológica tropical se ha documentado ampliamente el importante papel que las especies de Ficus (Moraceae) desempeñan en la diversidad, estructura y funcionamiento de las comunidades que habitan. Esta relevancia obedece principalmente a los higos que producen a lo largo del año, de los cuales dependen para su supervivencia una amplia gama de frugívoros, además de la excepcional interacción coevolutiva que las especies mantienen con sus avispas polinizadoras de la familia Agaonidae (Janzen, 1979; Wiebes, 1986; Herre, 1989; Ibarra-Manríquez, 1991; Compton et al., 1996; Shanahan et al., 2001). No se conoce con precisión la diversidad global de Ficus. Berg (1989) estima en alrededor de 750 el número de sus especies, por lo que se le considera el género con mayor número de representantes arbóreos del mundo (Carauta y Diaz, 2002), cuya distribución abarca el cinturón intertropical.

Por otro lado, Berg (1989) considera que el conocimiento taxonómico de las especies propias de Asia, Australia y África es aceptable, pero éste no es el caso para el Neotrópico, ya que a pesar de que existen algunos trabajos florísticos regionales, en ocasiones la circunscripción de las especies continúa siendo incierta. Berg (op. cit.) indica en el mencionado estudio que una adecuada definición de los componentes americanos del subgénero Pharmacosycea podría aportarse por medio de un trabajo monográfico que incluyera las 20 especies que tentativamente lo constituyen. Una situación diferente ocurre para el subgénero Urostigma, ya que si bien muchas de las 120 especies neotropicales son claramente distintas y fáciles de determinar, existen diversos complejos taxonómicos que hacen difícil o incluso imposible la determinación de sus miembros (ver p. ej. Burger, 1974; Berg y Simonis, 1981; Ibarra-Manríquez y Wendt, 1992; Carauta, 1996). 
Hasta el momento, sólo DeWolf (1965) ha publicado una monografía para Ficus cubriendo todo el territorio de América, aunque restringida a las especies del subgénero Pharmacosycea y en la que reconoce nueve especies, con 64 sinónimos. Otros trabajos florísticos que pueden mencionarse para el género en este continente son los hechos para Argentina (Vázquez, 1981), Belice (Balick et al., 2000), Brasil (Carauta, 1989; Carauta et al., 1996; Carauta y Diaz, 2002), Costa Rica (Burger, 1977; Hammel, 1986), Guatemala (Standley y Steyermark, 1946), Jamaica (Adams, 1972), Nicaragua (Todzia et al., 2001) y Panamá (DeWolf, 1960). A pesar de que las referencias mencionadas previamente pueden ser usadas para determinar las especies mexicanas de Ficus, no son lo suficientemente detalladas para permitir una identificación expedita y confiable de todos sus miembros.

La única revisión taxonómica que ha tratado de incluir a todas las especies mexicanas de Ficus fue elaborada por Standley (1922), basada en un trabajo previo que incluyó los taxa de México y Centroamérica (Standley, 1917). Varias décadas después, Ibarra-Manríquez y Wendt (1992) describieron cinco especies para el subgénero Pharmacosycea en Veracruz. Posteriormente, Carvajal (1995) propuso dos nuevas subespecies para $F$. insipida Willd. Carvajal y Peña-Pinela (1997) describieron una nueva especie ( $F$. jacquelineae), la cual está estrechamente relacionada con $F$. cotinifolia Kunth. Quintana y Carvajal (2001) publicaron un estudio para las 14 especies nativas de Ficus de Jalisco. En este mismo año, Carvajal y colaboradores establecieron nuevas combinaciones subespecíficas para F. cotinifolia y $F$. petiolaris, ambas pertenecientes al subgénero Urostigma. Carvajal (2001) discutió la validez del uso del nombre F. americana Aublet, en sustitución de $F$. perforata L. Finalmente, Serrato et al. (2004), en un análisis biogeográfico de Ficus en México, reconocieron 21 especies (seis endémicas al país), de las cuales cinco están incluidas en Pharmacosycea y 16 en Urostigma.

Para el estado de Morelos, Standley (1922) registró cuatro especies: Ficus cotinifolia Kunth, F. involuta (Liebm.) Miquel, F. padifolia Kunth y F. petiolaris Kunth. Subsecuentemente, en esta entidad se han realizado varios trabajos florísticos que mencionan representantes del género (p. ej. Vázquez, 1974; Soria, 1978; Flores, 1988; Maldonado, 1997; Cerros-Tlatilpa y Espejo, 1998; Fernández et al., 1998; Monroy y Colín, 1999; Galindo, 1999; Altamirano, 2001; Bonilla-Barbosa y Villaseñor, 2003; Piedra, 2004). Conjuntando la información de tales trabajos, se han citado 18 especies nativas y nueve cultivadas para esta entidad (Cuadro 1). Sin embargo, una revisión de los mapas de distribución aportados por Serrato et al. (2004) sugieren que este número de taxa para Morelos es excesivo. En consecuencia, el presente estudio tiene como objetivo básico realizar un estudio florístico de Ficus 
en Morelos, depurando la información existente y aportando herramientas que faciliten su determinación.

Cuadro 1. Especies nativas y cultivadas del género Ficus (Moraceae) citadas en la literatura florística del estado de Morelos.

\begin{tabular}{|l|l|}
\hline Nativas & \\
\hline F. citrifolia Mill. & F. obtusifolia Kunth \\
\hline F. cotinifolia Kunth & F. oerstediana Kunth \\
\hline F. glabrata Kunth & F. padifolia Kunth \\
\hline F. goldmanii Standl. & F. pertusa L.f. \\
\hline F. insipida Willd. subsp. insipida & F. petiolaris Kunth \\
\hline F. jaliscana S. Watson & F. radula Willd. \\
\hline F. maxima Mill. & F. segoviae Miq. \\
\hline F. mexicana (Miq.) Miq. & F. tolucensis (Liebm.) Miq. $*$ \\
\hline F. nymphaeifolia Mill. & F. velutina Kunth ex Willd. \\
\hline
\end{tabular}

\begin{tabular}{|l|l|}
\hline Cultivadas & \\
\hline F. benghalensis $\mathrm{L}$. & F. pandurata Hance \\
\hline F. benjamina $\mathrm{L}$ & F. religiosa $\mathrm{L}$. \\
\hline F. carica L. & F. retusa L. \\
\hline F. elastica Roxb. & F. pumila $\mathrm{L}$. \\
\hline F. lyrata Warb. & \\
\hline
\end{tabular}

* Este nombre es citado por error en Bonilla-Barbosa y Villaseñor (2003), ya que en realidad los autores deseaban referirse a F. tecolutensis (Liebm.) Miq. (J. L. Villaseñor, com. pers.).

\section{ÁREA DE ESTUDIO}

El estado de Morelos está situado en la parte central de la República Mexicana, entre los paralelos $18^{\circ} 20^{\prime}-19^{\circ} 07^{\prime} \mathrm{N}$ y los meridianos $98^{\circ} 37^{\prime}-99^{\circ} 30^{\prime} \mathrm{O}$ (Anónimo, 1981), con una extensión territorial de $4,960 \mathrm{~km}^{2}$; limita al norte con el Distrito Federal y 
el Estado de México, al sur-sureste con Guerrero y al este-sureste con Puebla, con altitudes que oscilan entre 700 y 5,000 m s.n.m. y un total de 33 municipios. En esta área se localizan dos provincias morfotectónicas (Ferrusquía-Villafranca, 1998): i) la Faja Volcánica Transmexicana, cuyas formas fisiográficas dominantes son producto de actividad eruptiva, por lo que está compuesta básicamente de cuerpos ígneos del Cenozoico Medio al Tardío y sedimentarios clásticos del Cenozoico Tardío, y ii) la Sierra Madre del Sur, considerada como una de las provincias más complejas del país, geológicamente poco conocida, de donde se han descrito cuerpos sedimentarios marinos y volcánicos del Mesozoico y Cenozoico. En la entidad se presentan diez unidades edáficas (Anónimo, 1981): andosoles, cambisoles, feozems, fluvisoles, litosoles, luvisoles, regosoles, rendzinas, vertisoles y xerosoles.

García (1981) define como principal tipo de clima para Morelos el A, cálido húmedo y subhúmedo, con temperatura media anual (TMA) mayor de $22{ }^{\circ} \mathrm{C}$. La autora indica la presencia de dos principales subgrupos climáticos: 1) cálido $\mathrm{A}$, con la temperatura del mes más frío mayor de $18^{\circ} \mathrm{C}$ (tres subtipos del clima Aw, caliente subhúmedo con lluvias de verano: $\left.\mathrm{Aw}_{0}{ }_{0}, \mathrm{Aw}_{1}, \mathrm{y} \mathrm{Aw}_{2}\right)$, y 2) semicálido $\mathrm{A}(\mathrm{C})$, con TMA entre $18-22{ }^{\circ} \mathrm{C}$, temperatura media del mes más frío mayor de $18{ }^{\circ} \mathrm{C}$ (dos subtipos $\mathrm{A}(\mathrm{C}) \mathrm{w}_{1}{ }_{1}$, y $\left.\mathrm{A}(\mathrm{C}) \mathrm{w}_{2}{ }_{2}\right)$. En el estado se encuentran además otros tipos de clima: 1) húmedo frío $\mathrm{E}(\mathrm{T})$, con la TMA menor de $-2{ }^{\circ} \mathrm{C}$, o el clima muy frío $\mathrm{EF}$, con la TMA entre $-2{ }^{\circ} \mathrm{C}$ y $5{ }^{\circ} \mathrm{C}, 2$ ) templado húmedo y subhúmedo $\mathrm{C}$, con la TMA entre 12 y $18{ }^{\circ} \mathrm{C}$, temperatura media del mes más frío entre $-3^{\circ} \mathrm{C}$ y $18{ }^{\circ} \mathrm{C}$, con una canícula o sequía de medio verano, y 3 ) semiseco BS, con cociente precipitación-temperatura mayor de 22.9, con régimen de lluvias de verano y precipitación anual inferior al valor obtenido del valor $r_{h}(2 T M A+28)$.

Respecto a la cobertura vegetal estatal, el número de categorías varía según el autor (p. ej. Miranda y Hernández-X., 1963; Rzedowski, 1978). Bonilla-Barbosa y Villaseñor (2003) reconocen 13 tipos de vegetación, sobresaliendo por su extensión el bosque tropical caducifolio y el bosque de pino-encino. Otras comunidades referidas en esta contribución son el bosque de Abies, bosque de galería, bosque mesófilo de montaña, bosque de Pinus, bosque de Quercus, matorral subtropical, matorral xerófilo, pastizal alpino y vegetación acuática. De acuerdo con su extensión territorial, Palacio-Prieto et al. (2000) indican las siguientes categorías de vegetación primaria para Morelos: selva baja caducifolia y subcaducifolia $\left(1,058 \mathrm{~km}^{2}\right)$, bosque de pino $\left(140 \mathrm{~km}^{2}\right)$, bosque de pino-encino o de encino-pino $\left(115 \mathrm{~km}^{2}\right)$, bosque de encino $\left(123 \mathrm{~km}^{2}\right)$, bosque mesófilo de montaña $\left(57 \mathrm{~km}^{2}\right)$, bosque de oyamel $\left(37 \mathrm{~km}^{2}\right)$ y matorral desértico rosetófilo $\left(2 \mathrm{~km}^{2}\right)$. 


\section{MATERIALES Y MÉTODOS}

Se llevó a cabo una búsqueda bibliográfica, así como una revisión del material botánico de las especies del género Ficus colectado en Morelos y depositado en los herbarios ENCB, HUMO, MEXU (incluye la colección L'Amagatall del Dr. José Vázquez), MORE (sin registro oficial, perteneciente al Centro de Investigaciones Biológicas de la Universidad Autónoma del Estado de Morelos) y UAMIZ. Lo anterior se complementó con expediciones botánicas a lo largo de la entidad. Las descripciones de las especies y la clave para su determinación se basan en todos los especímenes consultados e incluyen datos observados en material fresco (p. ej. color del látex). Los datos de distribución combinan la información encontrada en los ejemplares de herbario y bibliografía especializada (p. ej. Ibarra-Manríquez y Wendt, 1992; Quintana y Carvajal, 2001; Serrato et al., 2004). Los nombres comunes de cada especie se restringen a los registrados para el territorio de Morelos. Los nombres de las autoridades de los taxa están abreviados siguiendo a Villaseñor (2001). Los sinónimos están basados en Ibarra-Manríquez y Wendt (1992) y Quintana y Carvajal (2001). Los comentarios taxonómicos que se incluyen para las especies se basan principalmente en DeWolf (1960, 1965), Ibarra-Manríquez y Wendt (1992) y Quintana y Carvajal (2001), así como en observaciones realizadas por los autores.

\section{RESULTADOS}

La revisión de herbario y el trabajo de campo realizado para Morelos indican que en este territorio prosperan ocho especies nativas de Ficus, las cuales se ubican en dos subgéneros: Pharmacosycea (Ficus insipida Willd. y F. maxima Mill.) y Urostigma (F. cotinifolia Kunth, F. glycicarpa (Miq.) Miq., F. pertusa L.f., F. petiolaris Kunth, F. trigonata L. y Ficus sp.). De acuerdo con Serrato et al. (2004), $F$. glycicarpa y F. petiolaris son endémicas al territorio mexicano. A continuación se presenta la clave de identificación para los subgéneros y especies de Ficus, así como descripciones del género y de cada especie.

\section{FICUS L.}

Árboles o arbustos monoicos, terrestres, epífitos, rupícolas o “estranguladores", estos últimos con raíces aéreas que engruesan rodeando a la 
planta hospedera; corteza parda, gris o amarilla, con exudado lechoso; yema foliar terminal, cónica; estípulas dos por nudo, cónicas, rodeando completamente las yemas, usualmente caducas y dejando una cicatriz a manera de anillo que rodea el tallo; hojas alternas o en espiral, simples y pecioladas; la inflorescencia un receptáculo hueco que semeja un fruto (el sicono o higo), solitaria o en pares, sésil o pedunculada, con dos a tres brácteas basales subyacentes y con una pequeña abertura apical (el ostíolo), protegida por escamas que se traslapan entre sí; flores unisexuales, ubicadas sobre la pared interna del sicono, numerosas; el perianto de las estaminadas 2-8 dividido o indiviso, estambres 1-8, filamentos rectos, anteras introrsas y pistilodio presente o ausente; el perianto de las pistiladas 2-4 dividido, pistilo con un estilo lateral al ovario, 1-2 dividido; frutos drupas o aquenios pequeños, localizados dentro del sicono, el cual al madurar es indehiscente, de color verde o verde amarillo en Pharmacosycea, y verde, pardo negro, negro o rojo en Urostigma.

\section{Clave de los Subgéneros y Especies}

1. Árboles de crecimiento independiente, terrestres, no rupícolas; siconos solitarios en el nudo, verdes a verde amarillos; látex blanco .... Subgénero Pharmacosycea

2. Pecíolo liso o piloso; siconos verdes a verde amarillos, con máculas blancas o amarillas, glabros F. insipida

2. Pecíolo cubierto por pequeñas escamas de color oscuro, fácilmente caedizas al tacto; siconos verdes, sin máculas, pilosos F. maxima

1. Árboles a menudo epífitos, estranguladores o rupícolas; siconos geminados en el nudo, verdes a verde rojizos, verde amarillos o con tonalidades pardas; látex de color rosa, crema o blanco Subgénero Urostigma

3. Árboles de corteza amarilla; lámina de la hoja cordiforme, con un agregado de pelos blancos hacia la base del envés F. petiolaris

3. Árboles de corteza parda oscura o parda gris; lámina de la hoja no cordiforme, glabra o de ser pubescente, los pelos no restringidos exclusivamente a la base

4. Siconos sésiles; lámina elíptica, rectangular, elíptico circular o elíptico oblonga; yema foliar terminal densamente pubescente, no ferrugínea ..

5. Hojas con pecíolo y lámina de similar longitud; ramas huecas, ocupadas por hormigas; siconos de (8.6-)9.7-13 mm de diámetro ...... Ficus sp. 
5. Hojas con pecíolo de $1 / 3$ de longitud con respecto a la lámina; ramas sólidas; siconos de 4.8-9.1(-11.8) $\mathrm{mm}$ de largo ............. F. cotinifolia

4. Siconos pedunculados; lámina elíptico oblonga o lanceolada; yema foliar terminal glabra a ligeramente pubescente en la base, o de ser completamente pubescente, entonces ferrugínea .................................. 6

6. Yema foliar terminal ferrugínea; envés de la hoja densamente pubescente F. glycicarpa

6. Yema foliar terminal no ferrugínea; envés de la hoja glabro 7

7. Base y ápice de la hoja obtuso redondeados; sicono de más de $11 \mathrm{~mm}$ de diámetro, pilósulo, con máculas rojas o verde negras al madurar y ostíolo aplanado F. trigonata

7. Base de la hoja obtusa a obtuso aguda, ápice agudo acuminado; sicono de hasta $11 \mathrm{~mm}$ de diámetro, glabro, con máculas oscuras o negras al madurar y ostíolo ligera a profundamente hundido en una estructura tubular del receptáculo F. pertusa

Descripción de las Especies

Ficus cotinifolia Kunth, Nov. Gen. et Sp., 2:49, 1817. Urostigma cotinifolium (Kunth) Miq., London J. Bot., 6:530, 1847. (Figs. 1 a, b; 2 A)

Nombres comunes. Amate, amate blanco, amate prieto, cabrigo, texcalamate, tlaligo.

Árboles de 3-25 m de alto, con tallos monopódicos, algunos con oquedades y raíces aéreas; corteza lisa, pardo gris o parda oscura; exudado blanco a ligeramente amarillo, abundante; copa amplia y redondeada, verde opaca. Yema foliar terminal de (4.5-)5.3-10.5(-12.2) $\mathrm{mm}$ de largo x 2.8-5.5 $\mathrm{mm}$ de ancho, verde a verde amarilla en fresco, parda a parda grisácea en material seco, densamente pubescente; entrenudos de (9.5-)11-48.2(-62.12) $\mathrm{mm}$ de largo x (2-)2.9-6.8(-7.3) $\mathrm{mm}$ de ancho, verdes, que se tornan pardos oscuros y estriados en material seco, escasamente pubescentes. Pecíolo de (8.8-)11.1-48.6(-70.5) $\mathrm{mm}$ de largo x (0.9-)1.5-1.8 $\mathrm{mm}$ de ancho, verde amarillo en fresco, pardo en material seco, en algunas ocasiones con un canal somero en el lado adaxial, glabro o con pubescencia escasa; lámina foliar de 4.8-14 cm de largo x 3.8-8.4(-10) $\mathrm{cm}$ de ancho, 1.1-2 veces más larga que ancha, elíptica a rectangular, verde en fresco a parda en material seco, coriácea, en algunas ocasiones cartácea; base redondeada a cuneada; ápice redondeado a obtuso, en ocasiones mucronado; 


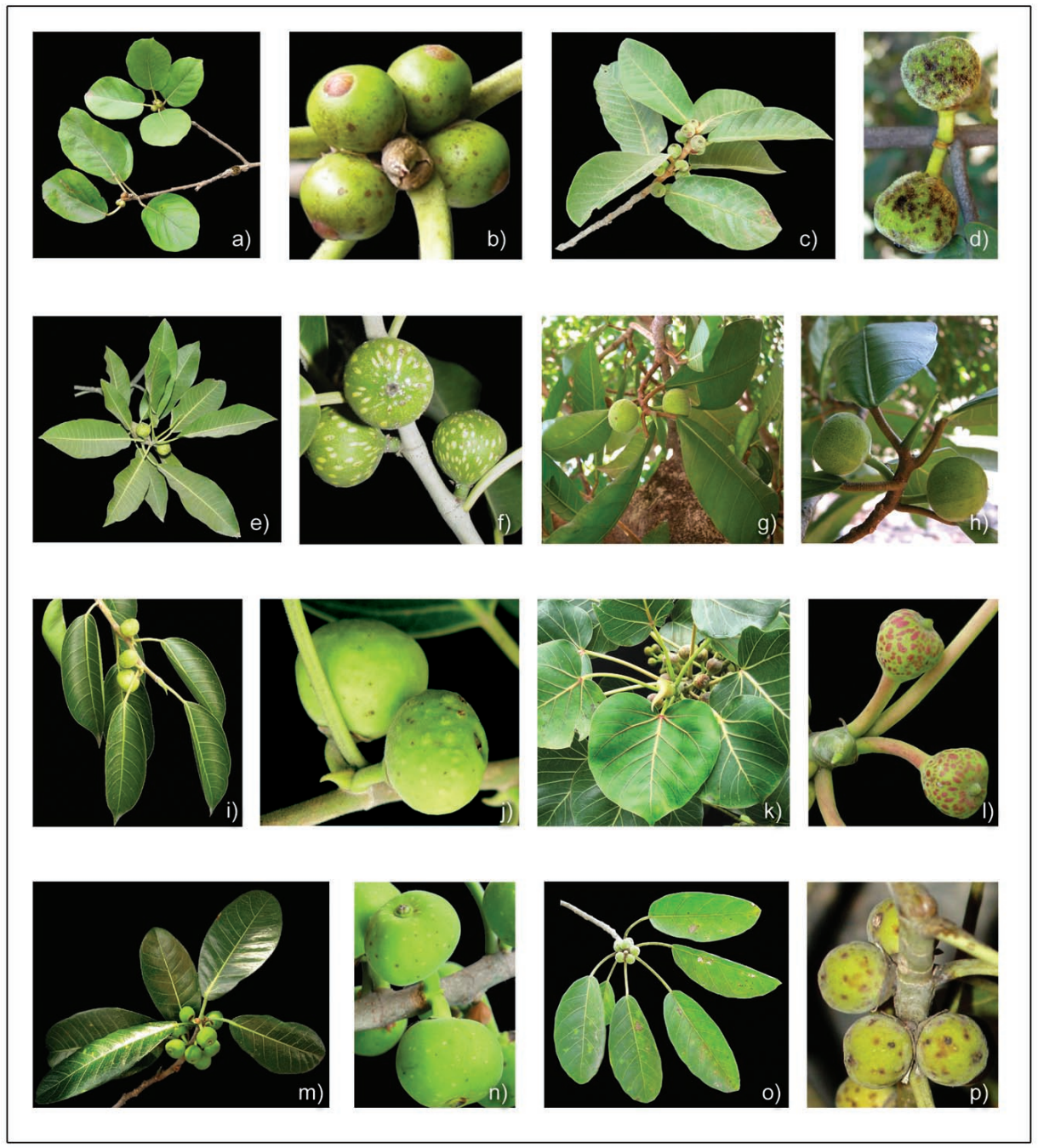

Fig. 1. Ramas y siconos de las especies de Ficus del estado de Morelos. Ficus cotinifolia (a, b), F. glycicarpa (c,d), F. insipida (e,f), F. maxima (g, h), F. pertusa (i, j), F. petiolaris $(\mathrm{k}, 1)$, F. trigonata (m, n) y Ficus sp. (o, p).

margen entero, verde opaco a verde amarillo; haz verde pardo, por lo general glabro y en pocas ocasiones ligeramente pubescente; envés verde o verde opaco, glabro a ligeramente pubescente, nervios laterales amarillos, 4 a 8 pares, opuestos en el primer par, los demás alternos. Estípulas de 5-12 mm de largo x 3-4 mm de ancho. Siconos 

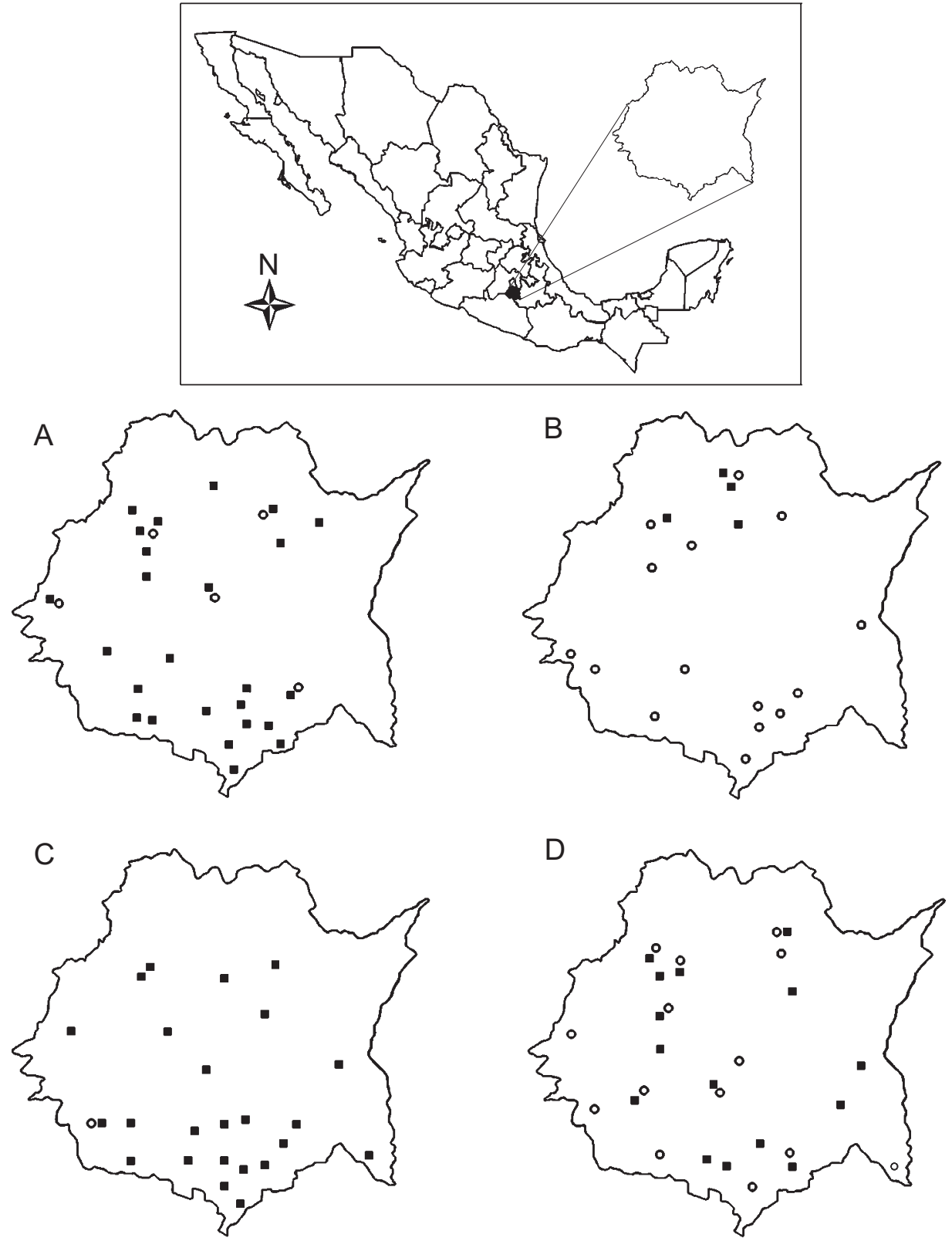

Fig. 2. Distribución geográfica conocida de las especies de Ficus presentes en el estado de Morelos. Ficus cotinifolia (A, $\mathbf{\square})$, F. glycicarpa $(\mathrm{B}, \mathbf{\square})$, F. insipida $(\mathrm{C}, \boldsymbol{\square})$, F. maxima $(\mathrm{C}, \circ), F$. pertusa $(\mathrm{D}, \mathbf{\square})$, F. petiolaris $(\mathrm{B}, \mathrm{O})$, F. trigonata $(\mathrm{D}, \mathrm{\circ})$ y Ficus sp. $(\mathrm{A}, \mathrm{o})$. 
geminados, sésiles, esferoides, de 4.8-9.1(-11.8) $\mathrm{mm}$ de largo x 5.4-9.9(-10.1) $\mathrm{mm}$ de ancho, verde a verde amarillos en fresco, oscuros en material seco, con máculas oscuras, ligeramente pubescentes, ostíolo de 1.1-3.2 $\mathrm{mm}$ de diámetro; brácteas basales de 2.1-5.7(-7) $\mathrm{mm}$ de largo x (1.4-)2.5-6.6(-7.1) $\mathrm{mm}$ de ancho, pardas, ápice redondeado, densamente pubescente, persistentes.

Árboles abundantes, estranguladores, epífitos o rupícolas, en bosque tropical caducifolio, bosque de galería y vegetación ruderal, entre 950 y 1750 m s.n.m. La floración y la fructificación se produce gran parte del año. Sin embargo, se observa una mayor abundancia de siconos de junio a diciembre. Especie de amplia distribución, desde México hasta Costa Rica. En México se extiende en la vertiente del Pacífico, de Sonora a Chiapas; en la vertiente del Golfo de México de Tamaulipas a Campeche; en el centro del país se localiza en Guanajuato, México, Morelos, Puebla y Querétaro. Fruto comestible y látex medicinal.

Ejemplares de esta planta han sido determinados incorrectamente como $F$. glaucescens (Liebm.) Miq., un sinónimo de F. maxima Mill. (Ibarra-Manríquez y Wendt, 1992). Otros nombres que se le han asignado son $F$. aurea Nutt., F. tecolutensis (Liebm.) Miq., F. jimenezii Standl. y F. kellermanii Standl. Todas estas especies tienen una delimitación poco clara y han sido mencionadas como sinónimos ( $\mathrm{p}$. ej. Balick et al., 2000 pero ver Burger, 1974; Berg, 1989). Otros especímenes de Morelos fueron determinados como F. subrotundifolia Greenm. Carvajal y PeñaPinela (1997) destacan que $F$. cotinifolia pertenece a un complejo taxonómico y que para su correcta delimitación requiere de un estudio que abarque toda su área de distribución (México a Costa Rica). Para México se han propuesto dos subespecies (cotinifolia y myxaefolia (Kunth) Carvajal), ambas registradas para Morelos por Carvajal et al. (2001). El material colectado en esta última entidad presenta una gran variación morfológica, particularmente en la pubescencia, tipos de ápices, tamaño y forma de las hojas, incluso en las hojas que se producen en una misma rama (Fig. 1a), por lo que no fue posible ubicarlo a nivel subespecífico (Cuadro 2). En Morelos, F. cotinifolia se caracteriza por sus hojas casi tan largas como anchas, desde pubescentes hasta casi glabras en el envés, siconos sésiles, geminados y yema foliar terminal densamente pubescente.

Mpio. Coatlán del Río: poblado de Coatlán del Río, B. Torres 92 (MEXU). Mpio. Cuautla: sierra de Tepoztlán, $6 \mathrm{~km}$ al NO de Oaxtepec, a $1.5 \mathrm{~km}$ al SE de la autopista México-Cuautla, D. H. Lorence 5023 (MEXU); cerca del poblado de Oaxtepec, $7.5 \mathrm{~km}$ por la carretera Cuautla-Tepoztlán, R. Palacios s. $n$. (ENCB). Mpio. Cuernavaca: sin localidad precisa, julio 29 de 1892, L. Gómez s. n. (MEXU); orillas de un canal de aguas negras, R. Palacios s. $n$. (ENCB); Salto de San Antón 
Cuadro 2. Atributos diagnósticos para determinar las subespecies de Ficus cotinifolia Kunth con base en Carvajal et al. (2001) y su comparación con los ejemplares de Morelos.

\begin{tabular}{|l|l|c|l|}
\hline \multicolumn{1}{|c|}{ Subespecies } & \multicolumn{1}{|c|}{$\begin{array}{c}\text { Base de la } \\
\text { lámina }\end{array}$} & $\begin{array}{c}\text { Largo del pecíolo } \\
(\mathrm{mm})\end{array}$ & \multicolumn{1}{|c|}{$\begin{array}{c}\text { Superficie de los } \\
\text { pecíolos }\end{array}$} \\
\hline cotinifolia & $\begin{array}{l}\text { truncada, } \\
\text { subtruncada o } \\
\text { redondeada }\end{array}$ & $30-80$ & glabra \\
\hline $\begin{array}{l}\text { myxaefolia } \text { (Kunth) } \\
\text { Carvajal }\end{array}$ & emarginada & $20-50$ & $\begin{array}{l}\text { densamente cubierta } \\
\text { por pelos simples, } \\
\text { blancos y por tricomas } \\
\text { capitados, cortos }\end{array}$ \\
\hline Ejemplares de Morelos & $\begin{array}{l}\text { redondeada o } \\
\text { cuneada }\end{array}$ & $(8.8-) 11.1-48.6(70.5)$ & $\begin{array}{l}\text { glabra o con } \\
\text { pubescencia escasa }\end{array}$ \\
\hline
\end{tabular}

(1855'32" N, 99¹4'62" W), E. M. Piedra 108 (HUMO). Mpio. Emiliano Zapata: al SE de Tetecalita rumbo a Temilcingo, R. Monrroy s. $n$. (MORE); colonia Bonifacio García, L. Vela s. n. (ENCB). Mpio. Jiutepec: Parque Nacional "El Tepozteco", I. J. De la Cruz 1498 (MORE, UAMIZ); área recreativa del Parque Nacional "El Tepozteco", L. E. Estrada 1117 (MEXU); lago Ahuayapan-Tejalpa, R. Medina 66 (UAMIZ); fraccionamiento Pedregal de las Fuentes (cerca de Cañón de Lobos), F. Miranda 9293 (MEXU); Pedregal de las Fuentes en calle San Gaspar, esquina Pedregal, E. M. Piedra 126, 127 (HUMO). Mpio. Jojutla: Cerro Grande, $1 \mathrm{~km}$ al E de Jojutla, J. Rzedowski 18684 (ENCB). Mpio. Puente de Ixtla: linderos del pueblo cerca del "corral de toros", sobre el arroyo, A. Bonfil 170 (UAMIZ); $1 \mathrm{~km}$ al SE de Tilzapotla camino a Cerro Frío, A. Bonfil 182 (UAMIZ); Xoxocotla, al oriente de terrenos de cultivo, H. N. Romero 102 (MEXU); Tehuixtla, balneario La Fundición, J. Rzedowski 18692 (ENCB, MEXU). Mpio. Temixco: llanos de Mejía, Acatlipa, J. Vázquez 3081 (MEXU). Mpio. Tepalcingo: cañada La Engorda, a $1.5 \mathrm{~km}$ al NE de El Limón, J. Bonilla 1421 (HUMO); El Limón, sobre la barranca del sendero ecológico (18³1'81" N, 9856'41" W), E. M. Piedra 148 (HUMO). Mpio. Tepoztlán: Coatetelco, a $500 \mathrm{~m}$ del pozo de Santa Catarina, al sur de la carretera principal Cuernavaca-Tepoztlán (1857'49" N, 9908'05" W), E. M. Piedra 97 (HUMO). Mpio. Tlaquiltenango: $3 \mathrm{~km} \mathrm{NE}$ de Huautla (18²7'14" N, 9902'33" W), R. Cerros T. 542 (HUMO); $1.5 \mathrm{~km}$ al NE de Xochipala (18²5'50" N, 9903'19" W), J. C. Juárez 171 (HUMO); $1.5 \mathrm{~km}$ al N de Santiopan (18²6'11" N, 98 57'30" W), B. Maldonado 
1245 (HUMO); Quilamula, R. Monroy s. n. (MORE); $100 \mathrm{~m}$ al SE del kiosco de Quilamula, E. M. Piedra 1 (HUMO); $5 \mathrm{~km}$ sobre el camino a Ajuchitlán del Crucero, E. M. Piedra 4 (HUMO); $0.6 \mathrm{~km}$ de la desviación hacia Ajuchitlán, E. M. Piedra 5 (HUMO); $500 \mathrm{~m}$ pasando la tranca de la Guayacanera, de la estación Cruz Pintada $\left(18^{\circ} 27^{\prime} 55^{\prime \prime} \mathrm{N}, 98^{\circ} 59^{\prime} 35^{\prime \prime} \mathrm{W}\right)$, E. M. Piedra 9 (HUMO); $300 \mathrm{~m}$ del camino a Huautla por el sendero (18 $\left.32^{\prime} 60^{\prime \prime} \mathrm{N}, 98^{\circ} 21^{\prime} 39^{\prime \prime} \mathrm{W}\right)$, E. M. Piedra 10 (HUMO); $10 \mathrm{~m}$ antes de la entrada de Santiopan (18²6'56" N, 98 57'80" W), E. M. Piedra 11 (HUMO); $1.5 \mathrm{~km}$ antes de Huaxtla, sobre el camino, E. M. Piedra 25 (HUMO); $25 \mathrm{~km}$ de Valle de Vázquez a Chimalacatlán, E. M. Piedra 34 (HUMO); $1.5 \mathrm{~km}$ adelante de Ajuchitlán, E. M. Piedra 50 (HUMO). Mpio. Tlaltizapán: $10 \mathrm{~m}$ de la entrada al club Manantiales de Ticumán (1844'17" N, 9906'79" W), E. M. Piedra 151 (HUMO).

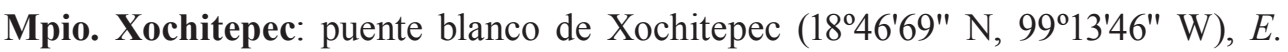
M. Piedra 120 (HUMO); montes de Xochicalco, J. Vázquez 2549 (MEXU). Mpio. Yautepec: cerca del poblado de Oaxtepec, km 7.5 carretera Cuernavaca-Tepoztlán, R. Palacios s. n. (ENCB). Mpio. Yecapixtla: carretera a Yecapixtla, O. Converse s. n. (MEXU).

Ficus glycicarpa (Miq.) Miq., Ann. Mus. Bot. Lugd.-Bat., 3:297, 1867. Urostigma glycicarpa [ut <glycicarpum $>$ ] Miq., Over. Versl. Meded. Konink. Akad. Wetensch. Natuur. Amsterdam, 13:411, 1862. F. jonesii Standl., Contr. U.S. Natl. Herb., 20:31, 1917. (Figs. 1 c, d; 2 B)

Nombres comunes. Amate, amate silvestre.

Árboles de 4-12 m de alto, con tallos monopódicos y con numerosas raíces aéreas, anastomosadas; corteza lisa, pardo gris o pardo roja; exudado blanco a ligeramente amarillo, abundante; copa amplia y densa, verde oscura. Yema foliar terminal de (7.4-)11-20.8(-22.1) mm de largo x (2.7-)3.1-4.8(-5.5) $\mathrm{mm}$ de ancho, pardo rojiza en fresco, parda a ferrugínea en seco, densamente serícea; entrenudos de (16.1-)20.2-38.2(-41.1) $\mathrm{mm}$ de largo x (2.9-)3.8-5.7(-7.6) $\mathrm{mm}$ de ancho, pardo grises en fresco a pardos en material seco, glabrescentes. Pecíolo de (8.5-)10-33.1(-35.9) $\mathrm{mm}$ de largo x (1.1-)1.7-3 mm de ancho, gris rojizo a pardo en fresco, casi negro en material seco, en algunas ocasiones con un canal somero en el lado adaxial, glabro o ligeramente piloso por el envés; lámina foliar de (7.5-)9.5-19.7(-22.5) cm de largo x (3.4-)4.3-8.5(-9.8) cm de ancho, (1.2-)1.7-2.6 veces más larga que ancha, elíptico oblonga, verde grisácea en fresco a parda en material seco, coriácea; base obtuso redondeada a ligeramente subcordada o emarginada; ápice obtuso redondeado a ligeramente cuspidado; margen entero, pardo; haz verde grisáceo a verde pardo, 
glabro; envés verde opaco a verde rojizo, densamente pubescente, nervios laterales de color oscuro, 8 a 17 pares, opuestos del primer hasta el tercer o cuarto par, después alternos. Estípulas de 9.5-27(-32.5) $\mathrm{mm}$ de largo x (2.5-)3.5-8.3(-10) $\mathrm{mm}$ de ancho. Siconos geminados, cortamente pedunculados, esferoides, de 10-15.2(-15.9) $\mathrm{mm}$ de largo x 9.6-10.8(-13.7) $\mathrm{mm}$ de ancho, verdes, con tricomas grises en fresco a pardos con máculas oscuras y tricomas grises en material seco, densamente pubescentes, ostíolo de 2.5-4.4 mm de diámetro; pedúnculo de 2.6-3.9(-4.6) mm de largo x 1.3-2.3 $\mathrm{mm}$ de ancho, verde en fresco, pardo en material seco, glabro a densamente piloso; brácteas basales de (1.2-)1.6-2.7(-3.1) $\mathrm{mm}$ de largo x 1.7-2.4(-2.9) $\mathrm{mm}$ de ancho, pardo rojizas en fresco, oscuras en material seco, cubiertas por una fina pubescencia ferrugínea, ápice redondeado, persistentes.

Árboles escasos, que habitan por lo general ecotonos de bosque tropical caducifolio y bosque de pino-encino, entre 1400 y 1700 m s.n.m. La floración y fructificación se presenta durante los meses de septiembre a febrero. Ficus glycicarpa es un elemento endémico a México, que se distribuye por la vertiente del Pacífico desde Sinaloa hasta Chiapas y por el Golfo de México en Veracruz. En el centro del país se encuentra en el Estado de México, Morelos y Puebla.

Ejemplares de herbario de esta planta han sido determinados como $F$. jonesii Standl., que es un sinónimo propuesto por Quintana y Carvajal (2001). De acuerdo con los mismos autores, esta especie se caracteriza por mostrar la siguiente combinación de atributos: hojas glabras, nervaduras del envés sobresalientes, epidermis de los pecíolos que se desprenden en pequeñas escamas y siconos ligeramente oblicuos, globosos. Ficus glycicarpa ha sido también confundida con F. microchamys Standl., F. pringlei S. Watson y Ficus velutina Standl., que son taxones similares y cuya delimitación es discutida por Quintana y Carvajal (2001). En Morelos, F. glycicarpa se caracteriza por tener las hojas glabras por el haz y con una pubescencia que va de ligera a densa en el envés, látex de color blanco a ligeramente amarillo, siconos pedunculados y yema foliar terminal densamente pubescente, ferrugínea.

Mpio. Cuernavaca: $50 \mathrm{~m}$ de la entrada de la barranca de Amanalco, E. $M$. Piedra 103 (HUMO); bajo el puente Porfirio Díaz en la Barranca de Amanalco, E. M. Piedra 104, 105 (HUMO); barranca del Salto de San Antón (1855'32" N, 99¹4'62" W), E. M. Piedra 106 (HUMO); barranca de Cuernavaca, R. Ramírez 2237 (HUMO). Mpio. Tepoztlán: Tepozteco, F. Miranda 1589 (MEXU); in the cerro Tepozteco above Tepoztlán ca. 30 km (18 $57^{\prime}$ N, 9908' W), J. Miller y R. Torres 3000 (MEXU); subida al Tepozteco (1859'46" N, 9965'97" W), E. M. Piedra 130 (HUMO); carretera federal Tepoztlán-Yautepec, en el poblado de Ixcatepec, sobre el río Atongo (1858'32" N, 9904'59" W), E. M. Piedra 135 (HUMO); Tepoztlán 
cerca de un cañón, $W$. $V$. Rodin 08 (MEXU). Mpio. Yautepec: Ojo de San Juan

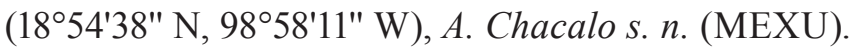

Ficus insipida Willd., Sp. Pl. ed. 4:1143. 1806. F. glabrata Kunth, Nov. Gen. Sp. 2:47, 1817. F. segoviae Miq., Ann. Mus. Bot. Lugduno-Batavum 3:300, 1868 (nomen novum para Pharmacosycea angustifolia Liebm.). Pharmacosycea angustifolia Liebm., Kongel. Danske Vidensk. Selsk. Skr., ser. 5, Naturvidensk. Math. Afh. 2:333, 1851 (non Ficus angustifolia Roxb., 1832). F. mexicana auct., non Miq. F. radulina S. Watson, Proc. Amer. Acad. Arts Sci. 26:151, 1891. (Figs. 1 e, f; 2 C)

Nombres comunes. Amate, amate blanco o higuera blanca.

Árboles de 4-30 m de alto, tallos monopódicos, fuste a veces pequeño, contrafuertes bien definidos; corteza lisa, pardo grisácea o parda pálida; exudado blanco, escaso en la corteza, pero abundante en la madera y en las ramas juveniles; copa densa y redondeada, verde pálida. Yema foliar terminal de (12-)23-83(-93) $\mathrm{mm}$ de largo x (0.7-)1.2-6 mm de ancho, verde a verde amarilla en fresco, obscura en material seco, glabra o pilosa en la base; entrenudos de (1.8-)3.9-30.2(-57.5) mm de largo x (1.0-)1.2-3.2(-5.8) $\mathrm{mm}$ de ancho, pardos, lisos cuando verdes, estriados en seco, glabros a densamente pilosos. Pecíolo de 5-7.1 mm de largo x (0.6-)0.82.7(-3.2) $\mathrm{mm}$ de ancho, verde en fresco a pardo pálido en material seco, glabro; lámina foliar de (2.8-)5.6-18.5(-23) cm de largo x 1.5-7(-13.6) cm de ancho, 2.34(-4.4) veces más larga que ancha, elíptico lanceolada, verde en fresco a verde opaca en material seco, coriácea; base atenuada; ápice acuminado, en algunas ocasiones apiculado; margen entero, verde opaco; haz verde amarillo, glabro a seríceo; envés verde amarillo pálido a verde pardo, glabro, nervios laterales amarillos, en algunas ocasiones levemente pardo rojizos, 9-18(-22) pares, alternos en el primer y segundo par, los demás opuestos. Estípulas de (10-)26-84.7(-88.8) mm de largo x (1.5-)2.96.5(-7.1) $\mathrm{mm}$ de ancho. Siconos solitarios, pedunculados, esferoides, de (7.8-)8.323.9(-29.3) $\mathrm{mm}$ de largo x (8.1-)8.6-24.8(-26.7) $\mathrm{mm}$ de ancho, verdes con máculas amarillas o blancas en fresco, pardos con máculas amarillas en material seco, glabros, de color rojo en su interior cuando frescos, ostíolo de (1.2-)1.8-4.4(-4.8) mm de diámetro; pedúnculo de (2.8-)3.2-8.3(-12.3) $\mathrm{mm}$ de largo x 1.4-3.9(-4.5) $\mathrm{mm}$ de ancho, verde en fresco a verde opaco en material seco, glabro a ligeramente piloso; brácteas basales de (0.8)1-2.7(-4) mm de largo x 1.6-4.3(-4.7) $\mathrm{mm}$ de ancho, verdes en fresco a pardas en material seco, con el ápice agudo, glabras y fácilmente caducas.

Árboles más o menos abundantes, que habitan preferentemente cerca de cuerpos de agua estacionales o permanentes, en bosque tropical caducifolio, bosque 
de galería, pastizal y vegetación ruderal, entre los 700 y 1350 m s.n.m. La floración y fructificación ocurre a lo largo del año, sin embargo, se observa un mayor número de siconos de octubre a enero. F. insipida es una especie de amplia distribución en el continente americano, que va desde el norte de México hasta Argentina. En México se le encuentra por la vertiente del Pacífico, desde Sonora hasta Chiapas, por la del Golfo de México en Tamaulipas y Veracruz y en el centro del país en Morelos, Puebla, Querétaro y San Luis Potosí. La especie tiene usos maderables, ornamentales y látex medicinal.

Los ejemplares colectados en Morelos de Ficus insipida han sido determinados como $F$. glabrata Kunth, F. radulina S. Watson y F. segoviae Miq., que son nombres actualmente considerados como sinónimos (Ibarra-Manríquez y Wendt, 1992; DeWolf, 1960; Quintana y Carvajal, 2001). También se ha citado para esta entidad a $F$. yoponensis Desv., que es un taxon relacionado, pero que puede distinguirse de $F$. insipida por tener siconos blancos en su interior y hojas obovadas (Ibarra-Manríquez y Wendt, 1992) y cuya presencia en Morelos se considera improbable. Otros nombres asociados al material de F. insipida son $F$. maxima Mill., una especie claramente distinta (ver la descripción correspondiente presentada más adelante), así como $F$. mexicana (Miq.) Miq., un sinónimo de este último taxon (Ibarra-Manríquez y Wendt, 1992). Las cuatro subespecies que se han propuesto para F. insipida por Berg et al. (1984) y Carvajal (1995) no presentan caracteres consistentes para diferenciarse en el material de Morelos (Cuadro 3), por lo que no se usan en el presente estudio. En Morelos, F. insipida es relativamente fácil de distinguir por la combinación de los siguientes caracteres: siconos verdes con máculas amarillas cuando frescos, de color rojo en su interior y una yema foliar terminal de hasta $9.3 \mathrm{~cm}$ de largo.

Mpio. Amacuzac: $10 \mathrm{~m}$ de la planta tratadora de agua $\left(18^{\circ} 35^{\prime} 91^{\prime \prime} \mathrm{N}\right.$, 99²2'30" W), E. M. Piedra 110 (HUMO). Mpio. Axochiapan: en las afueras del balneario "Los Amates" del poblado de Ahuaxtla, (18 $\left.28^{\prime} 89^{\prime \prime} \mathrm{N}, 98^{\circ} 45^{\prime} 79^{\prime \prime} \mathrm{W}\right), E$. M. Piedra 142 (HUMO). Mpio. Coatlán del Río: carretera Tetecala-Coatlán del Río (por Alpuyeca-Grutas), (1844'20" N, 99²5'47" W), E. M. Piedra 158 (HUMO). Mpio. Cuautla: "El Almeal”, H. Bravo s. n. (MEXU); Cuautla, F. Miranda 1337 (MEXU). Mpio. Cuernavaca: al S de Cuernavaca en el $\mathrm{km} \mathrm{93,} \mathrm{por} \mathrm{la} \mathrm{autopista}$ México-Acapulco, R. Palacios s. $n$. (ENCB). Mpio. Jonacatepec: $5 \mathrm{~km}$ al NE de Jonacatepec, L. González Q. 3633 (ENCB). Mpio. Puente de Ixtla: $1 \mathrm{~km}$ al SE, cerca de "Los Potreritos" en Tilzapotla, A. Bonfil 37 (ENCB, UAMIZ); sobre el río a $50 \mathrm{~m}$ de Tilzapotla, P. Castillo 40 (MORE); balneario "La Fundición", cerca de Tehuixtla, J. Rzedowski 18694 (ENCB). Mpio. Tepalcingo: rumbo a Los Sabinos, en la comunidad de El Limón, F. Camacho 1739 (MEXU); a un costado de la 
Cuadro 3. Caracteres usados para determinar las subespecies de Ficus insipida Willd. (Berg et al., 1984; Carvajal, 1995) y su comparación con los ejemplares revisados para Morelos.

\begin{tabular}{|l|c|l|}
\hline \multicolumn{1}{|c|}{ Subespecies } & \multicolumn{1}{|c|}{$\begin{array}{c}\text { Proporción largo x ancho } \\
\text { de la lámina }\end{array}$} & \multicolumn{1}{|c|}{ Ramillas de la estación } \\
\hline insipida Carvajal & $(1.2) 3.1$ & glabras \\
\hline radulina Carvajal & $(1.2) 3.1$ & $\begin{array}{l}\text { con pelos largos y } \\
\text { simples, blancos }\end{array}$ \\
\hline segoviae Carvajal & $3.8-4.6(-5.1)$ & $?$ \\
\hline scabra Berg & $?$ & $\begin{array}{l}\text { con pelos largos, erectos, } \\
\text { más o menos tiesos } \\
\text { (hirsutas) }\end{array}$ \\
\hline ejemplares de Morelos & $2.3-4(-4.4)$ & glabras o pilosas \\
\hline
\end{tabular}

presa, en la comunidad de El Limón (18³1'16" N, 9856'41" W), E. M. Piedra 153 (HUMO). Mpio Tlaquiltenango: Tilzapotla, P. Castillo s. $n$. (MORE); $6 \mathrm{~km}$ al E de la Estación Biológica “Cruz Pintada” (18²7'55" N, 9859'35" W), R. Castro Trejo 75 (HUMO); a $1.25 \mathrm{~km}$ al S de Huaxtla (18²2'11" N, 9903'05" W), J. C. Juárez 297 (HUMO); a $17.5 \mathrm{~km}$ al SE de Xochipala (18²4'15" N, 9902'17" W), G. Dante Ramírez 46 (HUMO); en la comunidad de "La Era", B. Maldonado s. n. (MORE); $0.5 \mathrm{~m}$ de la desviación a Ajuchitlán, E. M. Piedra 4 (HUMO); a $800 \mathrm{~m}$ de la entrada a Huautla, E. M. Piedra 8 (HUMO); a $5 \mathrm{~m}$ de la tranca a Huixaxtla, E. M. Piedra 27 (HUMO); a 25 km por el camino de Valle de Vázquez a Chimalacatlán, E. M. Piedra 30 (HUMO); a $30 \mathrm{~km}$ por el camino de Valle de Vázquez a Chimalacatlán, E. M. Piedra 32 (HUMO); a $12 \mathrm{~km}$ del camino de Los Hornos a Quilamula, E. M. Piedra 34 (HUMO). Mpio. Xochitepec: en el jardín del mercado de Xochitepec (1846.6'71" N, 99¹3'90" W), E. M. Piedra 122 (HUMO); Mpio. Yautepec: en las afueras de Yautepec, R. Palacios s. n. (ENCB); poblado de Oaxtepec, F. Miranda 1210 (MEXU). Mpio. indefinido: río de Tlaltizapán, J. Vázquez 2432 (MEXU).

Ficus maxima Mill., Gard. Dict. (ed. 8.), 1768. F. glaucescens (Liebm.) Miq., Ann. Mus. Bot. Lugduno-Batavum 3:300, 1868. Pharmacosycea glaucescens Liebm., Kongel. Danske Vidensk. Selsk. Skr., ser. 5, Naturvidensk. Math. Afh. 2:332, 1851. F. hernandezii (Liebm.) Miq., Ann. Mus. Bot. Lugduno-Batavum 3:300, 1868. Pharmacosycea hernandezii Liebm., Kongel. Danske Vidensk. Selsk. Skr., ser 5, 
Naturvidensk. Math. Afh. 2:332, 1851. F. mexicana (Miq.) Miq., Ann. Mus. Bot. Lugduno-Batavum 3:299, 1868. Pharmacosycea mexicana Miq., Verslagen Meded. Afd. Natuurk. Kon. Akad. Wetensch. 13:415, 1862. F. pseudoradula (Miq.) Miq., Ann. Mus. Bot. Lugduno-Batavum 3: 299, 1868. Pharmacosycea pseudoradula Miq., Verslagen Meded. Afd. Natuurk. Kon. Akad. Wetensch. 13:414, 1862. F. radula Humb. \& Bonpl. ex Willd., Sp. Pl. 4:1144. 1806. (Figs. 1 g, h; 2 C)

Nombre común. Amate.

Árboles de 5-25 m de alto, tallos monopódicos, fuste pequeño, contrafuertes bien definidos; corteza lisa, gris oscura; exudado blanco que se torna amarillo a medida que se expone al ambiente, abundante; copa abierta a ligeramente densa, redondeada, verde oscura. Yema foliar terminal de 15.6-20.5 mm de largo x 2.1-4.5 $\mathrm{mm}$ de ancho, verde oscura, ligeramente pubescente en la base; entrenudos de 19.9$30 \mathrm{~mm}$ de largo x 2-4.1 $\mathrm{mm}$ de ancho, pardos a pardo grisáceos, con la superficie exfoliante en pequeñas escamas irregulares, rugosos, ligeramente pubescentes. Pecíolo de 12.9-22 mm de largo x 2.1-4 mm de ancho, pardo, aplanado por el haz en fresco y con un canal a veces difícil de observar en material seco, con la superficie exfoliante formando pequeñas escamas irregulares, rugoso, glabro o ligeramente pubescente; lámina foliar de (9-)12.5-18.5 cm de largo x (3.6-)5.7-7.7 cm de ancho, 2.1-2.8 más larga que ancha, elíptica a elíptico lanceolada, verde oscura, crustácea; base cuneada; ápice acuminado; margen entero, verde oscuro; haz verde oscuro a verde grisáceo, glabro, en pocas ocasiones ligeramente pubescente; envés verde o verde opaco, glabro a ligeramente pubescente, nervios laterales verde amarillos a amarillos, 9 a 12 pares, alternos. Estípulas de 10-21 mm de largo x 2.5-5 mm de ancho. Siconos solitarios, pedunculados, globosos a esferoides, de $14-16 \mathrm{~mm}$ de largo x 12-15 mm de ancho, verdes opacos en fresco, pardos a negros en material seco; ligeramente pilosos, con una diminuta puberulencia visible al microscopio, de color rojo en su interior cuando frescos, ostíolo de 1.8-2 mm de diámetro; pedúnculo de 9-15 mm de largo x 1.5-3 mm ancho, verde pardo en fresco y completamente pardo en material seco, ligeramente piloso; brácteas basales de $1.5-2 \mathrm{~mm}$ de largo x 2.5-3 mm de ancho, verdes en fresco a pardas en material seco, ápice acuminado, densamente pubescentes, fácilmente caducas.

La especie es escasa en el bosque de galería y se colectó a 900 m s.n.m. El único ejemplar obtenido de esta árbol en Morelos fue observado con frutos durante febrero. Ibarra-Manríquez y Wendt (1992) mencionan que la floración y fructificación de $F$. maxima acontece durante todo el año. Se le localiza desde México hasta Argentina. En nuestro país se distribuye por la vertiente del Pacífico 
desde Sonora hasta Chiapas y por la del Golfo de México en Veracruz, Tabasco y Yucatán. En el centro del país se encuentra en Morelos y Puebla.

Ejemplares de $F$. insipida colectados en Morelos fueron incorrectamente determinados como $F$. glaucescens (Liebm.) Miq. y F. radula Willd., que son binomios designados como sinónimos de $F$. maxima (Ibarra-Manríquez y Wendt, 1992; Quintana y Carvajal, 2001), así como F. guajavoides Lundell, que es un taxon que no se ha registrado hasta el momento para México. Ficus maxima, aunque poco frecuente en Morelos, es una planta difícil de confundir con los otros miembros del género, debido a que posee los siguientes atributos: siconos de color rojo en su interior, con un ostíolo pequeño, una yema foliar terminal corta, así como la presencia de escamas exfoliantes epidérmicas a lo largo de sus pecíolos y ramas jóvenes.

Mpio. Amacuzac: sobre la calle Plan de Ayala, colonia El Balcedero (18³5'58" N, 99²2'58" W), E. M. Piedra 110, 157 (HUMO).

Ficus pertusa L. f., Suppl. Pl., 442, 1781. Urostigma baccatum Liebm., Kongel. Danske Vidensk. Selsk. Naturvidensk. Math. Afh., ser. 5, 2:327, 1851. F. baccata (Liebm.) Miq., Ann. Mus. Bot. Lugduno-Batavum., 3:298, 1867. (Figs. 1 i, j; 2 D)

Nombres comunes. Amate, amezquite, camichín, higo de campo, higuera, palo bolero, tlaxcalamate.

Árboles o arbustos comúnmente hemiepífitos, de (3-)6-15(-25) m de alto, tallos monopódicos o en pocas ocasiones simpódicos, cortos y huecos, con raíces aéreas; corteza lisa, pardo grisácea o verde grisácea; exudado blanco, escaso en la corteza, pero abundante en ramas juveniles; copa abierta y densa, verde a verde pálida. Yema foliar terminal de 5.5-15(-18.6) $\mathrm{mm}$ de largo x (0.6-)1.5-2.6 $\mathrm{mm}$ de ancho, parda a pardo amarilla, glabra a ligeramente pubescente; entrenudos de (12.7-)14.7-33.4 mm de largo x (1.2-)1.7-4.5(-5.4) $\mathrm{mm}$ de ancho, gris amarillos en fresco a pardo grisáceos en material seco, glabros. Pecíolo de (10.9-)12-26.5(-30) $\mathrm{mm}$ de largo x 0.5-1.6 mm de ancho, verde claro en fresco a pardo en material seco, con un canal profundo en el lado adaxial, glabro a ligeramente pubescente; lámina foliar de (3.4-)4.3-8.8 (-10) $\mathrm{cm}$ de largo x 1.5-3.3(-3.6) $\mathrm{cm}$ de ancho, (1.7-)1.8-2.5(-3) veces más larga que ancha, elíptica a elíptico oblonga, coriácea a papirácea; base obtusa a obtuso aguda; ápice agudo acuminado; margen entero, amarillo; haz verde amarillo, glabro; envés verde a verde opaco, glabro, nervios laterales amarillos, 6 a 10 pares, el primer par basal opuesto. Estípulas de 4.7-12.2 mm de largo x 0.9-11.0 mm de ancho. Siconos geminados, pedunculados, globosos a esferoides, de (4.2-)6.6-9.4(-11) mm de largo $\mathrm{x}$ 
(7.0-)7.2-10(-12.4) mm de ancho, verdes, con máculas rojas, las cuales son oscuras o negras al madurar, glabros, ostíolo de 3.1-4 $\mathrm{mm}$ de diámetro, ligera a profundamente hundido en una estructura tubular del receptáculo; pedúnculo de (2.9-)3.2-8.5(-9.7) $\mathrm{mm}$ de largo x 0.6-1.6 $\mathrm{mm}$ de ancho, verde amarillo en fresco a pardo en material seco, glabro; brácteas basales de (0.9-)1.1-3(-3.2) mm de largo x (0.7-)1.1-2.6(-3.1) mm de ancho, amarillas en fresco a pardo amarillas en material seco, ápice agudo, glabras, poco persistentes.

La especie habita en bosque tropical caducifolio, pastizales, vegetación secundaria y ruderal, entre los 980 y 1250 m s.n.m., y florece y fructifica principalmente de septiembre a noviembre; durante el resto del año se reproduce de manera infrecuente. Ficus pertusa presenta una amplia distribución, desde México hasta el sur de Brasil y Jamaica. En nuestro país se localiza en la vertiente del Pacífico desde Sonora hasta Chiapas; en la del Golfo de México se le encuentra desde Tamaulipas hasta Yucatán; en el centro del país se registra en Guanajuato, Morelos, Puebla, Querétaro y San Luis Potosí. El fruto es comestible y el látex presenta propiedades medicinales.

El material colectado en Morelos ha sido determinado incorrectamente como F. yoponensis Desv., un taxon perteneciente al subgénero Pharmacosycea (IbarraManríquez y Wendt, 1992). De acuerdo con Berg y Simonis (1981), F. pertusa forma parte de un complejo de taxa que incluyen, entre otras especies, a $F$. broadwayi Urban, F. padifolia Kunth, F. pallida Vahl, F. schumacheri (Liebm.) Miq., F. trachylesyce Dugand y F. zuliensis Berg \& Simonis. La mayoría de las formas de este complejo presentan frecuentemente higos maculados, con el ostíolo hundido en una estructura tubular del receptáculo; las dos principales formas se separan por tener generalmente siconos menores de $1 \mathrm{~cm}$ de largo (México a Brasil y Jamaica) o bien siconos $\geq$ de $1 \mathrm{~cm}$ de largo (México a Venezuela y Brasil), pero Berg y Simonis (1981) indican que este carácter es muy variable. Es por ello que algunos autores pueden reconocerlas como entidades distintas (p. ej. Berg et al., 1984; Quintana y Carvajal, 2001) o bien como sinónimos, usando como nombre válido a $F$. pertusa (p. ej. DeWolf, 1960; Burger, 1977; Balick et al., 2000). En este trabajo se adopta la última postura, considerando la carencia de criterios sólidos y constantes para separar las dos entidades. En Morelos, F. pertusa se caracteriza por su lámina lanceolada, siconos pequeños y pedunculados, verdes con máculas rojizas, con el ostíolo ligeramente hundido.

Mpio. Cuautla: en la comunidad de Cuautla, F. Miranda 1357 (MEXU); Cuautla, M. Sánchez s. n. (ENCB). Mpio. Cuernavaca: F. Moctezuma s. $n$. (MEXU). Mpio. Jiutepec: área recreativa del Parque Nacional "El Tepozteco", 
Gutiérrez 798 (MEXU). Mpio. Jonacatepec: $6 \mathrm{~km}$ al NE de Jonacatepec, $L$. González 3625 (ENCB). Mpio. Puente de Ixtla: río Tembemebe, sin colector y sin número (MEXU); Xoxocotla, J. Vázquez 1841 (HUMO). Mpio. Tlayacapan: cerca del la carretera Xochimilco-Oaxtepec, M. Ortiz 414 (ENCB, MEXU). Mpio. Tepalcingo: Tepalcingo, F. Miranda 1368 (MEXU). Mpio. Temixco: casa particular en la calle Lázaro Cárdenas en la colonia Azteca, E. M. Piedra 124 (HUMO). Mpio. Tlaquiltenango: SE del kiosco de Quilamula, E. M. Piedra 2 (HUMO); $35 \mathrm{~m}$ después de la tranca de Huixaxtla, E. M. Piedra 28 (HUMO); jardinera del centro de Chimalacatlán, E. M. Piedra 40 (HUMO). Mpio. Xochitepec: mercado municipal de Xochitepec, F. M. Fuchs 1735 (MEXU, UAMIZ); Xochitepec, R. Palacios s. $n$. (ENCB). Mpio. Zacapetec: $7 \mathrm{~km}$ al E de Alpuyeca, R. Palacios s. $n$. (ENCB).

Ficus petiolaris Kunth, Nov. Gen. Sp. 2:49, 1817. Urostigma petiolaris (Kunth) Miq., London J. Bot., 6:527, 1847. F. petiolaris subsp. palmeri (S. Watson) Felger \& Lowe, J. Ariz. Acad. Sci., 6(1):83, 1970. F. petiolaris subsp. brandegeei (Standl.) Felger \& Lowe, J. Ariz. Acad. Sci., 6(1):83, 1970. (Figs. 1 k, 1; 2 B)

Nombres comunes. Amate amarillo, tezcalamate.

Árboles de 8-30 m de alto, tallos monopódicos o simpódicos, cortos, con raíces aéreas que se anastomosan; corteza que se desprende fácilmente en escamas, amarilla; exudado blanco a blanco amarillo, abundante; copa escasa a muy amplia, verde opaca a verde amarilla. Yema foliar terminal de 14-27.3(-50) $\mathrm{mm}$ de largo $\mathrm{x}$ (3.2-)4-8.5(-9.5) $\mathrm{mm}$ de ancho, amarilla o rojiza en fresco, parda en material seco, glabra o ligeramente pilosa; entrenudos de (1.2-)9.3-31(-36) mm de largo x (3.9-)4.57.8(-9) $\mathrm{mm}$ de ancho, amarillos a amarillo grisáceos, lisos cuando verdes, estriados en seco, glabros o pubescentes. Pecíolo de (47-)61-143 mm de largo x 1.2-2.3 mm de ancho, verde amarillo en fresco, pardo en material seco, con un canal profundo en el lado adaxial, glabro; lámina (4.6-)6.3-13.5 cm de largo x (4.3-)6.5-14.3(-17.7) cm ancho, de 0.8-1.5 más larga que ancha, cordiforme, verde en fresco, verde oscura en material seco, coriácea; base hendida; ápice redondeado apiculado; margen entero, amarillo; haz verde amarillo en fresco, opaco a verde oscuro en material seco, glabro; envés verde amarillo, con un agregado de pelos blancos en la base, nervios laterales rojizos en hojas nuevas, amarillos al madurar, de 5 a 9 pares, comúnmente opuestos sólo en el primer par. Estípulas de 16-23.5 mm de largo x 3.1-8.3 mm de ancho. Siconos geminados, pedunculados, esferoides, de 9.2-13.7 mm de largo x 8.6-14.5 $\mathrm{mm}$ de ancho, verde amarillos con máculas oscuras en fresco, pardos en material seco, glabros, ostíolo de 1.6-3.4 mm de diámetro; pedúnculo (2.1-)5.3-15 mm de largo 
x 1.3-1.9(-2.1) $\mathrm{mm}$ de ancho, verde amarillo en fresco a oscuro en material seco, glabro; brácteas basales de 2-5 $\mathrm{mm}$ de largo x 2.4-5 $\mathrm{mm}$ de ancho, verde amarillas a amarillas en fresco, oscuras en material seco, con el ápice redondeado, glabras, persistentes.

Árboles más o menos abundantes, que habitan principalmente sobre rocas en cañadas y barrancas, en zonas de transición entre bosque tropical caducifolio y bosque de encino, también en bosque tropical caducifolio y bosque de galería, entre los 900 y 1300 m s.n.m. La floración y fructificación se registra principalmente en los meses de julio a noviembre. Ficus petiolaris es una especie endémica a México y es cultivada en el estado de Río de Janeiro, Brasil, para uso ornamental (Carauta y Diaz, 2002). En México se distribuye en la vertiente del Pacífico desde Baja California hasta Oaxaca y en la del Golfo de México en Veracruz; en el centro del país se le ha registrado para el Estado de México y Morelos. Esta especie es el "amate", con cuyas fibras floemáticas se prepara el "papel amate", usado desde la época precolombiana para ceremonias religiosas y actualmente para elaborar artesanías (Seemann, 1990). El látex de esta especie tiene propiedades medicinales antihelmínticas.

Para Morelos se encontró material de herbario determinado como Ficus jaliscana S. Watson, un sinónimo de $F$. petiolaris subsp. jaliscana (S. Watson) Carvajal (Carvajal et al., 2001). Con base en esta última referencia, la subespecie jaliscana se distingue por presentar ramillas de la estación densamente piloso seríceas, nervaduras de las hojas rojas o rosadas y siconos pubescentes o de ser glabros, no moteados, mientras que la subespecie petiolaris tiene ramillas de la estación glabras, nervaduras de las hojas amarillas y siconos glabros, moteados. Los ejemplares colectados en Morelos se asemejan en primera instancia a la primera de estas subespecies, pero existen individuos que pueden presentar ramillas de la estación glabras o pubescentes. Un carácter distintivo adicional para la subespecie jaliscana es que sus nervaduras son rojas, un atributo que en los individuos de Morelos sólo se presenta en estadios jóvenes, ya que cuando maduran se tornan amarillas. Ante la carencia de caracteres que separen de manera consistente a estas subespecies, se consideró conveniente no intentar separar el material morelense a nivel infraespecífico. En la zona de estudio esta planta se distingue fácilmente por su llamativa corteza amarilla y sus hojas cordiformes, con un agregado de pelos por el envés de las axilas de las nervaduras basales.

Mpio. Amacuzac: carretera federal a Taxco (18³6'44" N, 99²2'92" W), E. M. Piedra 156 (HUMO); Huajintlán, carretera Cuernavaca-Taxco, S. Zárate 1224 (MEXU). Mpio. Cuernavaca: Cuernavaca, S. Gómez s. n. (MEXU); Cuernavaca, 
F. Moctezuma s. n. (HUMO); Salto de San Antón (1855'24" N, 99¹4'28" W), E. M. Piedra 106 (HUMO); cerca de Cuernavaca, A. Reyes 1996 (MEXU). Mpio. Jiutepec: área recreativa del Parque Nacional "El Tepozteco", L. Estrada 1165 (MEXU, UAMIZ); sobre la carretera Jiutepec-Emiliano Zapata, frente a la calera grande, E. M. Piedra 128 (HUMO); al lado oeste del municipio, B. Maldonado (MORE). Mpio. Jojutla: en la ladera NE arriba del campo de tiro, I. Rivera 79 (MEXU). Mpio. Jonacatepec: carretera federal Tepalcingo-Jonacatepec, (18 39'57" N, 9949'67" W), E. M. Piedra 144 (HUMO). Mpio. Puente de Ixtla: a $2 \mathrm{~km}$ del camino El Salto-Tilzapota, en Tilzapotla, E. M. Piedra 68 (HUMO). Mpio. Tepalcingo: a un costado de la presa de El Limón (18³1'16", 9856'19"), E. M. Piedra 149 (HUMO). Mpio. Tlaquiltenango: Quilamula, R. Monroy s. $n$. (MORE); $0.7 \mathrm{~km}$ de la desviación a Ajuchitlán, E. M. Piedra 6 (HUMO); $3.5 \mathrm{~km}$, del camino Huaxtla-Xochipala, en Huaxtla, E. M. Piedra 46 (HUMO); $1 \mathrm{~km}$ al E de Huautla (18²2'54" N, 99³0'13" W), A. Ramírez 679 (HUMO); $2 \mathrm{~km}$ al NE de Huautla (18²6'29" N, 99²1'24" W), A. Valdez 259 (HUMO). Mpio. Xochitepec: Xochitepec, E. Lyonnet s. n. (MEXU). Mpio Yautepec: Oaxtepec, J. Vázquez 4730 (MEXU); Cañón de Lobos, F. Miranda s. n. (MEXU), R. Palacios s. $n$. (ENCB).

Ficus trigonata L., Pl. Surin. 17:145. 1775 (Figs. 1 m, n; 2 D)

Nombres comunes. Amate, amate prieto o texcalamate.

Árboles de 3-25 m de alto, tallos monopódicos, fuste a veces pequeño, con raíces aéreas y en ocasiones con contrafuertes bien definidos; corteza lisa, oscura; con exudado blanco en la corteza y ramas juveniles, que se torna rosada al contacto con el aire, abundante; copa densa, redondeada, verde oscura. Yema foliar terminal de (8.5-)9-27(-30) $\mathrm{mm}$ de largo x (2-)3.1-6.3(-10) $\mathrm{mm}$ de ancho, verde oscura en fresco a pardo rojiza en material seco, ligeramente pubescente; entrenudos de (8-)12$50.1 \mathrm{~mm}$ de largo x (2.0-)4-9.5(-11) $\mathrm{mm}$ de ancho, pardo rojizos en fresco a pardo grisáceos en material seco, glabros a ligeramente pilosos. Pecíolo de 13.8-50(-59) $\mathrm{mm}$ de largo x 1.4-3 mm de ancho, verde en fresco a pardo en material seco, pilósulo; lámina de (2.6-)5.3-18.3(-27) cm de largo x 3.5-8.9(-11) cm de ancho, 1.8-2.9(-3.6) más larga que ancha, elíptica a elíptico oblonga u ovada, verde oscura en fresco, parda en material seco, coriácea; base obtuso redondeada; ápice obtuso redondeado a ligeramente mucronado; margen entero, de color pardo rojizo; haz verde a pardo rojizo, glabro; envés pardo verde, glabro a ligeramente pubescente, nervios laterales amarillos a pardos oscuros, 6 a 14 pares, el primer par opuesto, alternos del segundo en adelante. Estípulas de 8-14 mm de largo x 3-4 mm de ancho. Siconos geminados, 
pedunculados, esferoides, de (9-)11-24(-32) mm de largo x (10.23-)12-27(-31) $\mathrm{mm}$ de ancho, verdes con máculas rojas en fresco o pardos con máculas oscuras y satinados en material seco, pilósulos, ostíolo de 1.7-6 mm de diámetro; pedúnculo de (3.6-)4-21(-24) $\mathrm{mm}$ de largo x 1.3-2.9(-3.3) $\mathrm{mm}$ de ancho, verde en fresco a pardo en material seco, glabro a densamente piloso; brácteas basales de (2.8-)3.3-5.8(-6.8) mm de largo x 2.2-6.5 mm de ancho, rojizas, ápice redondeado, glabras por el haz y pubescentes por el envés, persistentes.

Árboles abundantes que habitan preferentemente en cañadas y barrancas en medio del bosque tropical caducifolio y bosque de galería; también son un elemento frecuente en la vegetación ruderal y zonas de cultivo, entre los 850 y $1600 \mathrm{~m}$ s.n.m. La floración y fructificación se produce en casi todo el año, con una mayor abundancia entre los meses de octubre a enero. Esta especie se distribuye desde México hasta Venezuela y Ecuador. En nuestro país se localiza en la vertiente del Pacífico desde Sonora hasta Chiapas y en la del Golfo de México en Veracruz; en el centro se le encuentra en Morelos, Puebla y Zacatecas. El látex de F. trigonata se usa como medicinal.

Ejemplares de esta especie provenientes de Morelos han sido determinados erróneamente como $F$. cotinifolia Kunth. Otros nombres también usados son $F$. guadalajarana S. Watson, F. mexicana (Miq.) Miq. y F. glaucescens (Liebm.) Miq., los cuales son sinónimos de F. maxima Mill. (DeWolf, 1960; Ibarra-Manríquez y Wendt, 1992; Quintana y Carvajal, 2001). F. trigonata forma parte de un complejo taxonómico que incluye $F$. morazoniana (Todzia et al., 2001), F. gomelleira Kunth \& Bouché, F. bullenii I.M. Johnston y F. popenoei Standl. (Berg y Simonis, 1981), así como F. goldmanii Standl. y F. williamsii Standl. (Balick et al., 2000, pero ver Quintana y Carvajal, 2001), el cual se caracteriza por sus hojas de tamaño medio a largo y siconos subsésiles o cortamente pedunculados, con un anillo circular o triangular alrededor del ostíolo (Berg y Simonis, 1981). En consecuencia, el nombre de $F$. trigonata se usa provisionalmente hasta que no se aclare la delimitación de este complejo de especies. En la zona de estudio F. trigonata se caracteriza por sus hojas elíptico oblongas, glabras o cubiertas con una pubescencia en el envés, base de la hoja obtuso redondeada, siconos que al madurar presentan máculas pardo rojas, yema foliar terminal glabra y látex que se torna rosado al contacto con el aire.

Mpio. Amacuzac: calle Plan de Ayala, colonia El Balcedero (18³5'99" N, 99²2'46" W), E. M. Piedra 112, 114 (HUMO); pastizal secundario, J. Rzedowski

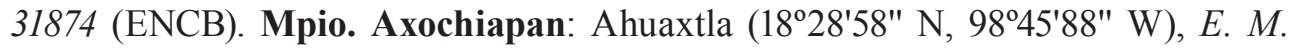
Piedra 143 (HUMO). Mpio. Coatlán del Río: Coatlán del Río, B. Torres 414 
(MEXU). Mpio. Cuernavaca: a un lado de una casa cerca de la cascada Cuernavaca, F. Miranda 224 (MEXU); Cuernavaca, F. Moctezuma s. n. (MEXU); panteón de La Leona (18 55'57" N, 99¹4'54" W), E. M. Piedra 109 (HUMO). Mpio. Jiutepec: 1 km al E del zócalo de Jiutepec (1853'10" N, 99¹0'18" W), E. M. Piedra 99 (HUMO). Mpio. Jojutla: hidroeléctrica de Amacuzac (Tlatenchi), P. Gutiérrez s. n. (MORE, UAMIZ). Mpio. Puente de Ixtla: linderos del pueblo cerca del corral de toros, en Tilzapotla, A. Bonfil 176 (UAMIZ); a $500 \mathrm{~m}$ del entronque camino a El Salto, en Tilzapotla, E. M. Piedra 55 (HUMO); sin localidad precisa, al oriente de terreno de cultivo, Romero et al. 102 (MEXU, MORE). Mpio. Temoac: carretera federal Temoac-Zacualpan, frente al auditorio municipal de Temoac (18 $46^{\prime} 16^{\prime \prime} \mathrm{N}, 98^{\circ} 46^{\prime} 50^{\prime \prime}$ W), E. M. Piedra 147 (HUMO). Mpio. Tepoztlán: $0.5 \mathrm{~km}$ al S de la carretera principal Cuernavaca-Tepoztlán a un costado de la granja El Polvorín (18 ${ }^{\circ} 57^{\prime} 49^{\prime \prime}$ N, 9908'06" W), E. M. Piedra 96 (HUMO). Mpio. Tlaltizapán: balneario Santa Isabel (18 44'37" N, 9906'85" W), E. M. Piedra 155 (HUMO); exactly half way

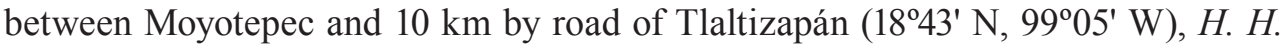
Iltis y S. Solheim 3015 (MEXU). Mpio. Tlaquiltenango: $3.5 \mathrm{~km}$ al SE de Ajuchitlán (18 $27^{\circ} 72^{\prime \prime}$ N, 98 56'32" W), R. Cerros 695 (HUMO); sobre el primer vado de la calle principal en Huautla (18 $30^{\prime} 58^{\prime \prime}$ N, 99 $9^{\circ} 4^{\prime} 27^{\prime \prime}$ W), E. M. Piedra 3 (HUMO); $500 \mathrm{~m}$ antes de la entrada a Ajuchitlán, E. M. Piedra 7 (HUMO); en la tranca de la entrada a Santiopan (18²6'56" N, 98 57'58" W), E. M. Piedra 13 (HUMO); 1 $\mathrm{km}$ antes de Xochipala, E. M. Piedra 49 (HUMO). Mpio. Tlayacapan: a $10 \mathrm{~m}$ del puente Tepatitlán, en la colonia Tepatitlán (1855'07" N, 9859'50" W), E. M. Piedra 118 (HUMO). Mpio. Xochitepec: balneario Palo Bolero, P. Gutiérrez 1510 (HUMO); puente blanco de Xochitepec (1846'07" N, 99¹3'47" W), E. M. Piedra 119 (HUMO). Mpio. Yautepec: a 9 km de Yautepec, por Tepoztlán, P. Gutiérrez 980 (MEXU, UAMIZ); Oaxtepec, F. Miranda 1198 (MEXU); avenida Nacional, en casa particular (1854'36" N, 9868'13" W), E. M. Piedra 139 (HUMO).

Ficus sp. (Figs. 1 o, p; 2 A)

Nombres comunes. Amate, amate blanco, amate prieto.

Árbol de 10-40 m de alto, tallos monopódicos con oquedades y con numerosas raíces aéreas; corteza lisa, gris brillante a pardo grisácea; exudado blanco a ligeramente amarillo, escaso; copa amplia y redondeada, con ramas huecas ocupadas por hormigas. Yema foliar terminal de (10.7-)12.3-15 mm de largo x (2.7-)4.5-6.3(-7) $\mathrm{mm}$ de ancho, verde a verde amarilla en fresco, parda a pardo grisácea en material seco, densamente pubescente; entrenudos de (18.1-)22-36(-47.5) $\mathrm{mm}$ de largo x 
(3.9-)4.2-6.2(-7.5) $\mathrm{mm}$ de ancho, verdes a verde pardos en fresco y pardos oscuros, estriados en material seco, glabros. Pecíolo de (12.6-)44-100(-120) mm de largo x 1.7-2.3 mm de ancho, verde amarillo en fresco, pardo en material seco, en algunas ocasiones con un canal somero en el lado adaxial, glabro o ligeramente pubescente; lámina (6.5-)11.5-14.5 cm de largo x (3.5-)6.2-8.7(-9.5) cm de ancho, 1.2-1.6(-1.8) más larga que ancha, elíptico circular a elíptico oblonga, verde en fresco a verde parda en material seco, coriácea; base redondeada a subcordada, en ocasiones ligeramente hendida; ápice redondeado a ligeramente cuspidado; margen entero, amarillo; haz verde pálido, glabro; envés verde o verde opaco, glabro, nervios laterales amarillos, 6 a 11 pares, el primer par opuesto, los demás alternos. Estípulas de (3.2-)7-14 mm de largo x (2-)4-6.3(-7) mm de ancho. Siconos geminados, sésiles, esferoides, de (8.6-) 9.7-13 mm de largo $\mathrm{x}(10-) 11.8(-13.5) \mathrm{mm}$ de ancho, amarillos, verde amarillos o pardo amarillos, con máculas, glabros, ostíolo de 2.5-4 mm de diámetro; brácteas basales de (2.7-)4.2-5.5(-6) $\mathrm{mm}$ de largo x 4.6-5.2 $\mathrm{mm}$ de ancho, pardas, con el ápice redondeado, densamente pubescentes, persistentes.

Árboles escasos, que habitan principalmente en bosque tropical caducifolio, bosque de galería y vegetación ruderal, entre los 990 y los 1537 m s.n.m. Se reproduce durante gran parte del año, pero particularmente de noviembre a febrero. Hasta el momento sólo se conocen colectas para Morelos y Jalisco.

Materiales de esta especie han sido determinados como F. cotinifolia Kunth, F. isophlebia Standl. y F. lentiginosa Vahl. Ficus sp. es similar a F. costaricana (Liebm.) Miq., la que se caracteriza por tener pecíolos más cortos, hojas con el ápice acuminado y la base levemente hendida, con las brácteas basales de los siconos cubriéndolos hasta su parte intermedia. Ejemplares de Ficus sp. también se han determinado como $F$. irinae Carvajal, un binomio que no ha sido publicado hasta el momento. En Morelos, esta especie se caracteriza por sus pecíolos tan largos o casi tan largos como la lámina (aunque la imagen de la Fig. 1 o no representa claramente esta característica, se trata de un rasgo evidente en el campo y en los ejemplares de herbario), siconos moteados de un color satinado, yema foliar terminal glabra a ligeramente pubescente, pero sobre todo por sus ramas huecas ocupadas por hormigas, un carácter que nunca antes se había descrito para ninguna especie mexicana.

Mpio. Coatlán del Río: carretera Tetecala-Coatlán (por Alpuyeca-Grutas), (18²3'89" N, 99²4'83" W), E. M. Piedra 159 (HUMO). Mpio. Jiutepec: $1 \mathrm{~km}$ al E del zócalo de Jiutepec, en la calle India Bonita del Frac. El Zapote (1853'10" N, 99¹0'19" W), E. M. Piedra 100 (HUMO). Mpio. Tlaltizapán: balneario Santa Isabel (184'37" N, 9906'85" W), E. M. Piedra 154 (HUMO). Mpio. Tlaquiltenango: 3.5 
km al NE de Ajuchitlán (18²9'31" N, 9857'32" W), R. Cerros 404 (HUMO). Mpio. Yautepec: avenida Nacional de Oaxtepec (18 $54^{\prime} 36^{\prime \prime} \mathrm{N}, 9^{\circ} 68^{\prime} 13^{\prime \prime}$ W), E. M. Piedra 139 (HUMO).

\section{DISCUSIÓN Y CONCLUSIONES}

A pesar de que Morelos es una de las entidades más pequeñas de México, fue evidente la falta de información florística para evaluar claramente la riqueza del género Ficus en su territorio, ya que varios de los epítetos específicos usados en la literatura o en el material de herbario consultado son sinónimos o determinaciones incorrectas. Un ejemplo de esta situación es $F$. maxima, la cual fue registrada para la flora de Morelos por Fernández et al. (1998) y Bonilla-Barbosa y Villaseñor (2003). Sin embargo, todos los ejemplares determinados con este nombre corresponden a $F$. insipida. Es a partir de la presente investigación que es posible registrar con certeza la presencia de F. maxima para el estado, ya que esta especie carecía anteriormente de ejemplares colectados para el área de estudio en los herbarios consultados. Algunos taxa citados en la literatura florística para Morelos permanecen en un estado de incertidumbre, tal es el caso de F. obtusifolia Kunth, cuya presencia es indicada por Standley (1922), citando el sinónimo F. involuta (Liebm.) Miq. y que carece de ejemplares de herbario que documenten su presencia en el territorio morelense. Otras especies en esta situación, pero de presencia muy improbable en Morelos, son F. citrifolia Mill., F. nymphaeifolia Mill. y F. tecolutensis (Liebm.) Miq., cuyas poblaciones se localizan generalmente en bosques tropicales cálido húmedos. El hallazgo en este estudio de ejemplares de Ficus sp. es notable, ya que posiblemente se trate de una novedad para la ciencia, relacionada principalmente con F. membranacea C. Wright, una planta distribuida en Sudamérica.

Las discusiones que acompañan las descripciones de las especies incluidas en este trabajo ejemplifican la complejidad taxonómica del género Ficus. Se ha planteado que esta problemática tiene relación con la escasez de material de herbario para muchas de sus especies y a la limitada información sobre diversos aspectos de su ecología, especialmente sobre los patrones de asociación con sus polinizadores de la familia Agaonidae (Berg y Simonis, 1981; Berg, 1989; Ibarra-Manríquez y Wendt, 1992), los cuales generalmente están asociados con una sola especie de Ficus (Wiebes, 1986; Herre, 1989; Compton et al., 1996). Lo anterior significa que una delimitación más precisa de los representantes neotropicales de Ficus requiere no sólo de una cuidadosa revisión del material de colecciones de herbario que cubran 
todo el ámbito geográfico de cada taxon, sino también de estudios sobre biología de la polinización de las avispas Agaonidae y genéticos, basados en marcadores moleculares (e. gr. Herre et al., 1996; Weiblen, 2000). A pesar de lo anterior, es importante destacar que las especies encontradas en Morelos presentan caracteres vegetativos y reproductivos útiles para su determinación, lo que se espera estimule la realización de estudios similares en otras localidades de México. Los resultados de la presente contribución son una evidencia adicional de la necesidad de continuar efectuando estudios florísticos y sistemáticos que contribuyan al conocimiento de la diversa e interesante flora del estado de Morelos.

\section{AGRADECIMIENTOS}

Se dan las gracias al Dr. Eleazar Carranza González por sus acertadas críticas para mejorar una primera versión del trabajo y al Biól. Armando Aguirre Jaimes, por su entusiasta participación en el trabajo de campo. De igual forma, los atinados comentarios de dos revisores anónimos ayudaron a mejorar el manuscrito.

\section{LITERATURA CITADA}

Adams, C. D. 1972. Flowering plants of Jamaica. University of the West Indies, Mona. pp. 219-224.

Altamirano, J. D. 2001. Manual de plantas urbanas del centro histórico de Cuernavaca. Tesis de maestría. Facultad de Arquitectura, Universidad Autónoma del Estado de Morelos. Cuernavaca, Morelos. 197 pp.

Anónimo. 1981. Síntesis geográfica de Morelos. Secretaría de Programación y Presupuesto. Instituto Estatal de Estadística, Geografía e Informática. México, D.F. 110 pp.

Balick, M. J., M. H. Nee y D. E. Atha. 2000. Checklist of the vascular plants of Belize with common names and uses. Mem. N. Y. Bot. Gard. 85: 1-246.

Berg, C. C. 1989. Classification and distribution of Ficus. Experientia 45: 605-611.

Berg, C. C. y J. F. Simonis. 1981. The Ficus flora of Venezuela: five species complexes discussed and two new species described. Ernstia 6: 1-11.

Berg, C. C., M. Vázquez A. y F. Kooy. 1984. Ficus species of Brazilian Amazonia and the Guianas. Supl. Acta Amazonica 14(1/2): 159-194.

Bonilla-Barbosa, J. y J. L. Villaseñor. 2003. Catálogo de la flora del estado de Morelos. Centro de Investigaciones Biológicas, Universidad Autónoma del Estado de Morelos, México. Cuernavaca, Morelos. 129 pp. 
Burger, W. C. 1974. Ecological differentiation in some congeneric species of Costa Rican flowering plants. Ann. Missouri Bot. Gard. 61: 297-306.

Burger, W. C. 1977. Moraceae. In: Burger, W. (ed.). Flora Costaricensis. Fieldiana Bot. 40: 94-215.

Carauta, P. P. J. 1989. Ficus (Moraceae) no Brasil: conservação e taxonomia. Albertoa 2: $1-365$.

Carauta, P. P. J. 1996. Moráceas do estado do Rio de Janeiro. Albertoa 4(13): 145-194.

Carauta, P. P. J., C. Sastre y S. R. Neto. 1996. Índice das espécies de moráceas do Brasil. Albertoa 4(7): 77-93.

Carauta, P. P. J. y B. E. Diaz. 2002. Figueiras no Brasil. Editora Universidade Federal do Rio de Janeiro. Rio de Janeiro. 211 pp.

Carvajal, S. 1995. Nuevas combinaciones en especies del género Ficus L. (Moraceae, subgen. Pharmacosycea) de México. Bol. Inst. Bot. Univ. Guadalajara 1(7): 477-484.

Carvajal, S. 2001. Ficus americana Aublet or F. perforata L. (Moraceae). Bol. Inst. Bot. Univ. Guadalajara 8(1-2): 169-173.

Carvajal, S. y C. Peña-Pinela. 1997. Ficus jacquelineae (Moraceae, subgénero Urostigma). A new name for a Mexican fig. Bol. Inst. Bot. Univ. Guadalajara (4): 57-60.

Carvajal, S., R. Rivera-Espinosa y H. Palacios-Juárez. 2001. Nuevas combinaciones en especies del género Ficus L. subgénero Urostigma (Moraceae) de México. Bol. Inst. Bot. Univ. Guadalajara 8(1-2): 127-136.

Cerros-Tlatilpa, R. y A. Espejo. 1998. Contribución al estudio florístico de los cerros "El Sombrerito" y "Las Mariposas" (Zoapapalotl) en el municipio de Tlayacapan, Morelos, México. Polibotánica 8: 29-46.

Compton, S. G., J. T. Wiebes y C. C. Berg. 1996. The biology of fig trees and their associated animals. J. Biog. 23: 405-407.

DeWolf, Jr. G. P. 1960. Ficus (Tourn.) L. In: Woodson Jr., R. E. y R. W. Schery (eds.). Flora of Panama. Ann. Missouri Bot. Gard. 47(4): 146-165.

DeWolf, Jr. G. P. 1965. Ficus, subgenus Pharmacosycea in America. Elliottia 4: 1-20.

Fernández, R., C. Rodríguez, L. M. Arreguín y A. Rodríguez. 1998. Listado florístico de la Cuenca del Río Balsas, México. Polibotánica 9: 1-151.

Ferrusquía-Villafranca, I. 1988. Geología de México: una sinopsis. In: Ramamoorthy, T. P., R. Bye, A. Lot y J. Fa (comps.). Diversidad biológica de México. Orígenes y distribución. Instituto de Biología, Universidad Nacional Autónoma de México. México, D.F. pp. 3-108.

Flores, C. A. 1988. Los árboles ornamentales de la ciudad de Cuernavaca, Morelos. Tesis de licenciatura. Facultad de Ciencias Biológicas, Universidad Autónoma del Estado de México. Cuernavaca, Morelos. 205 pp.

Galindo B. G. 1999. Inventario florístico del municipio de Amacuzac, Morelos. Tesis de licenciatura. Escuela Nacional de Ciencias Biológicas, Instituto Politécnico Nacional. México, D.F. 62 pp.

García, E. 1981. Modificaciones al sistema de clasificación climática de Köppen (para adaptarlo a las condiciones de la República Mexicana). Talleres de Offset Larios S. A. México, D.F. 252 pp. 
Hammel, B. E. 1986. The vascular flora of La Selva Biological Station, Costa Rica. Selbyana 9: 192-195.

Herre, E. A. 1989. Coevolution of reproductive characteristics in 12 species of New World figs and their pollinators wasps. Experientia 45: 637-647.

Herre, E. A., C. A. Machado, E. Bermingham, J. D. Nason, D. M. Windsor, S. S. McCafferty, W. van Houten y K. Bachmann. 1996. Molecular phylogenies of figs and their pollinator wasps. J. Biog. 23: 521-530.

Ibarra-Manríquez, G. 1991. Ficus (Moraceae): un género interesante para estudios en ecología y sistemática tropical. Ciencia 42(3): 283-293.

Ibarra-Manríquez, G. y T. L Wendt. 1992. El género Ficus, subgénero Pharmacosycea (Moraceae) en Veracruz, México. Bol. Soc. Bot. México 52: 3-29.

Janzen, D. H. 1979. How to be a fig. Ann. Rev. Ecol. Syst. 10: 13-51.

Maldonado. B. 1997. Aprovechamiento de los recursos forestales de la Sierra de Huautla, Morelos, México. Tesis de maestría. Universidad Nacional Autónoma de México. México, D.F. 149 pp.

Miranda, F. y E. Hernández-X. 1963. Los tipos de vegetación de México y su clasificación. Bol. Soc. Bot. México 28: 29-179.

Monroy, R. y H. Colín. 1999. Cerro de la Tortuga, municipio de Zacatepec, Morelos, México: Área Sujeta a Conservación Ecológica. Centro de Investigaciones Biológicas. Universidad Autónoma del Estado de Morelos. Cuernavaca, Morelos. 28 pp.

Palacio-Prieto, J. L., G. Bocco, A. Velázquez, J. F. Mas, F. Takaki-Takaki, A. Victoria, L. LunaGonzález, G. Gómez-Rodríguez, J. López-García, M. Palma M., I. Trejo-Vázquez, A. Peralta H., J. Prado-Molina, A. Rodríguez-Aguilar, R. Mayorga-Saucedo y F. González-Medrano. 2000. La condición actual de los recursos forestales en México: resultados del Inventario Forestal Nacional 2000. Investigaciones Geográficas, Bol. Inst. Geog. UNAM 43: 183-203.

Piedra M., E. M. 2004. El género Ficus (Moraceae) en el estado de Morelos. Tesis de licenciatura. Facultad de Ciencias Biológicas, Universidad Autónoma del Estado de Morelos. Cuernavaca, Morelos. 71 pp.

Quintana, C. R. y S. Carvajal. 2001. Las especies jaliscienses del género Ficus L. (Moraceae). Bol. Inst. Bot. Univ. Guadalajara 8(1-2): 1-64.

Rzedowski, J. 1978. Vegetación de México. Ed. Limusa. México, D.F. 432 pp.

Serrato, A., G. Ibarra-Manríquez y K. Oyama. 2004. Biogeography and conservation of the genus Ficus (Moraceae) in Mexico. J. Biog. 31: 475-485.

Seemann, E. 1990. Usos del papel en el calendario ritual mexica. Colección Científica 207. Instituto Nacional de Antropología e Historia. México, D.F. 159 pp.

Shanahan, M., Samson, S., Compton, S. G. y R. Corlett. 2001. Fig-eating by vertebrate frugivores: a global review. Biol. Rev. 76: 529-572.

Soria, G. 1978. Contribución al conocimiento de la Flora del "Cañón de Lobos” Morelos. Tesis de licenciatura. Escuela de Ciencias Biológicas, Universidad Autónoma del Estado de Morelos. Cuernavaca, Morelos. 136 pp.

Standley, P. C. 1917. The Mexican and Central American species of Ficus. Contr. U. S. Nat. Herb. 20(1): 1-35. 
Standley, P. C. 1922. Ficus. In: Trees and shrubs of Mexico. Contr. U. S. Nat. Herb. 23(1): 205-213.

Standley, P. C. y J. A. Steyermark. 1946. Moraceae. In: Flora of Guatemala. Fieldiana Bot. 24(4): 10-58.

Todzia, C., W. D. Stevens y A. Pool. 2001. Moraceae. In: Stevens, W. D., C. Ulloa U., A. Pool y O. M. Montiel (eds.). Flora de Nicaragua (Angiospermas, Fabaceae-Oxalidaceae). Monographs Syst. Bot. Missouri Bot. Gard. 85: 1513-1539.

Vázquez S. J. 1974. Contribución al estudio de las plantas del estado de Morelos (México). Catálogo de las plantas contenidas en el Herbario “L' Amagatall”. Ciencia (México) 29: 1-138.

Vázquez, A. M. D. 1981. El género Ficus (Moraceae) en la República de Argentina. Darwiniana 23(2-4): 605-637.

Villaseñor, J. L. 2001. Catálogo de autores de plantas vasculares de México. Instituto de Biología, Universidad Nacional Autónoma de México y Comisión Nacional para el Conocimiento y Uso de la Biodiversidad. México, D.F. 40 pp.

Weiblen, G. D. 2000. Phylogenetic relationships of functionally dioecious Ficus (Moraceae) based on ribosomal DNA sequences and morphology. Am. J. Bot. 87(9): 1342-1357.

Wiebes, J. T. 1986. The association of figs and fig-insects. Rev. Zool. Afri. 100: 63-71.

Recibido en enero de 2005.

Aceptado en noviembre de 2005. 